\title{
DFT Study of Binding and Electron Transfer from a Metal-Free Dye with Carboxyl, Hydroxyl, and Sulfonic Anchors to a Titanium Dioxide Nanocluster
}

\author{
Corneliu I. Oprea, ${ }^{1}$ Petre Panait, ${ }^{1}$ Jeanina Lungu, ${ }^{1}$ Daniela Stamate, ${ }^{2}$ Anca Dumbravă, ${ }^{2}$ \\ Fanica Cimpoesu, ${ }^{3}$ and Mihai A. Gîrţu ${ }^{1}$ \\ ${ }^{1}$ Department of Physics, Ovidius University of Constanţa, 900527 Constanţa, Romania \\ ${ }^{2}$ Department of Chemistry, Ovidius University of Constanţa, 900527 Constanţa, Romania \\ ${ }^{3}$ Department of Theoretical Chemistry, Institute of Physical Chemistry, 060021 Bucharest, Romania
}

Correspondence should be addressed to Mihai A. Gîrţu; girtu@univ-ovidius.ro

Received 14 February 2013; Accepted 9 April 2013

Academic Editor: Theodoros Dimopoulos

Copyright (c) 2013 Corneliu I. Oprea et al. This is an open access article distributed under the Creative Commons Attribution License, which permits unrestricted use, distribution, and reproduction in any medium, provided the original work is properly cited.

\begin{abstract}
We report results of density functional theory (DFT) calculations of a metal-free dye, 5-(4-sulfophenylazo)salicylic acid disodium salt, known as Mordant Yellow 10 (MY-10), used as sensitizer for $\mathrm{TiO}_{2}$ dye-sensitized solar cells (DSSCs). Given the need to better understand the behavior of the dyes adsorbed on the $\mathrm{TiO}_{2}$ nanoparticle, we studied various single and double deprotonated forms of the dye bound to a $\mathrm{TiO}_{2}$ cluster, taking advantage of the presence of the carboxyl, hydroxyl, and sulfonic groups as possible anchors. We discuss various binding configurations to the $\mathrm{TiO}_{2}$ substrate and the charge transfer from the pigment to the oxide by means of DFT calculations. In agreement with other reports, we find that the carboxyl group tends to bind in bidentate bridging configurations. The salicylate uses both the carboxyl and hydroxyl substituent groups for either a tridentate binding to adjacent $\mathrm{Ti}(\mathrm{IV})$ ions or a bidentate Ti-O binding together with an $\mathrm{O}-\mathrm{H}-\mathrm{O}$ binding, due to the rotation of the carboxyl group out of the plane of the dye. The sulfonic group prefers a tridentate binding. We analyze the propensity for electron transfer of the various dyes and find that for MY-10, as a function of the anchor group, the DSSC performance decreases in the order hydroxyl + carboxyl > carboxyl $>$ sulfonate.
\end{abstract}

\section{Introduction}

Dye-sensitized solar cells (DSSCs) have attracted considerable interest over the last years, as they offer the advantages of low fabrication costs, transparency, and flexibility, when desired [1]. For such reasons, DSSCs may constitute a choice for affordable low-power generation in urban areas and in particular a possibility of producing power generating windows $[2,3]$.

The working principle of the DSSCs is based on light absorption in a dye anchored on $\mathrm{TiO}_{2}$ anatase nanoparticles, followed by transfer of the photoelectron from the dye to the wide bandgap semiconductor and through the transparent conducting oxide to the external load; at the counter electrode, the redox electrolyte facilitates the transport of the electron back to the dye and the regeneration of the sensitizer, through reduction of the triiodide ion at the counter electrode, followed by oxidation of the iodide ion at the dye $[1,4]$. The efficiency of the photovoltaic device depends strongly upon the dye and electrolyte used [5-7]. The highest efficiencies, of over $12 \%$, have been obtained using metal complexes [8], and values above $9 \%$ have been obtained also with organic dyes [9-11].

An efficient solar cell sensitizer should demonstrate (i) strong adsorption to the semiconductor surface through anchoring groups, (ii) intense absorption in the visible part of the spectrum, (iii) proper energy level alignment of the excited state of the dye and the conduction band edge of the semiconductor, as well as the redox level of the electrolyte and the ground state of the dye, (iv) fast charge transfer from the dye to the substrate, with low loss of photoelectrons, and (v) electrochemical and thermal stability $[1,4,12]$. 
The anchoring modes of the dye to the $\mathrm{TiO}_{2}$ surface are of crucial importance, the bonding type and the extent of electronic coupling between the dye excited state and the semiconductor unoccupied states influencing directly the overall cell performance $[1,4,13]$. Anchoring to $\mathrm{TiO}_{2}$ has been achieved through a number of functional groups [14-16], such as carboxylic acid, sulfonic acid, phosphonic acid, acetylacetonate derivatives, and salicylate the most widely used and successful to date being the carboxylic acid [4]. Some derivatives of carboxylic acid, such as ester, acid chloride, acetic anhydride, carboxylate salt, amide, or silane have also been used as anchoring groups [4, 17].

The standard anchoring group for sensitizers is carboxylic acid $(-\mathrm{COOH})[4,11]$, as so far the best photovoltaic conversion efficiencies have been obtained with dyes bound to the substrate through carboxylic acid groups $[5,8]$. The carboxylic acid groups, while ensuring efficient adsorption of the dye on the surface, also promote electronic coupling between the donor levels of the excited chromophore and the conduction band of the $\mathrm{TiO}_{2}$ nanoparticles. Early experimental studies indicated various anchoring configurations, ranging from monodentate ester-like binding [18], bidentate bridging [19], or both bidentate chelate and bridging [20]. More sensitive experiments [21] showed that $63 \%$ of surface binding arises from ester formation, 34\% from chelating and bridging, and $3 \%$ from anion and hydrogen bonding.

Efficient anchoring with phosphonic acid has been obtained for a ruthenium(II) complex with terpyridine [22], which allowed for a binding to $\mathrm{TiO}_{2}$ stronger than the typical N3 dye [5] with carboxylic acid groups. The sulfonic group was used as anchor for several porphyrinand phthalocyanine-based dyes [23] as well as for some polypyridyl complexes [24] but it has been systematically outperformed by the carboxyl group.

The salicylate has been reported in several studies $[25,26]$ regarding adsorption to $\mathrm{TiO}_{2}$. A comparative study of the surface complexation of colloidal titanium dioxide by monodentate and bidentate benzene derivatives (benzoic acid, phthalic acid, isophthalic acid, terephthalic acid, salicylic acid, and catechol) [25] showed that there is a sharp acceleration of the electron transfer in the presence of the bidentate ligands salicylate and phthalate, whereas the monodentate complexant benzoate exhibits practically no effect.

Another interesting experimental study [27] introduced carboxyl, hydroxyl, and/or sulfonate anchoring groups onto the skeletons of some hemicyanine-based organic dyes. It was shown that the incident photon-to-current conversion efficiencies (IPCE) for the photoelectrodes and the overall photovoltaic conversion efficiencies of the DSSCs depended strongly on the anchoring group types and decreased in the order carboxyl + hydroxyl > carboxyl $>$ sulfonate + hydroxyl [27].

The fast electron transfer in the case of bidentate salicylate ligand [25] and the higher performance of the dyes with both carboxyl and hydroxyl anchoring groups [27] has led us to revisit an earlier study [28] of a 5-(4-sulfophenylazo)salicylic acid disodium salt dye, known as Mordant Yellow 10 (MY-10). Based on a combined experimental and theoretical approach, we explained puzzling results regarding the correlation between the $\mathrm{pH}$ of the solution and the photovoltaic conversion efficiency of the device. Despite the relatively low efficiency, initially attributed to the weak optical absorption in the visible range and the unoptimized fabrication procedures, MY-10 provides an interesting opportunity for the study of the role of dye deprotonation on the device efficiency as well as the influence of the energy difference between the excited state of the dye and the conduction band edge of the oxide on the short circuit current of the DSSC. More importantly, on the topic of adsorption to the substrate, MY-10 offers a chance to study the various ways of binding to the $\mathrm{TiO}_{2}$ and compare, for that purpose, the $-\mathrm{OH},-\mathrm{CO}_{2} \mathrm{H}$, and $-\mathrm{SO}_{3} \mathrm{H}$ groups.

Our approach is inspired by the early theoretical studies on dyes with $-\mathrm{COOH}$ anchors [29], which showed by means of density functional theory (DFT) calculations that the preferred binding configuration of the carboxyl group is bidentate bridging. More recently extended theoretical modeling [30] demonstrated that for the dyes bearing a carboxylic acid as anchoring group, the preferred adsorption mode is bidentate bridging, with one proton transferred to a nearby surface oxygen, while the monodentate anchoring is usually predicted to be less stable [31-33]. Moreover, DFT and timedependent DFT (TD-DFT) methods allowed for the description not only of the absorption spectrum of the dye but also of the more complex system consisting of the dye, and the $\mathrm{TiO}_{2}$ cluster. The bonding of the dye on the nanoparticle, the alignment of the energy levels of the two subsystems, and the transfer of the electron from the dye to the cluster have all been successfully calculated by means of a DFT approach $[34,35]$.

We report here results of DFT and TD-DFT calculations performed on complex systems consisting of the MY-10 dye and $\mathrm{a} \mathrm{TiO}_{2}$ nanocluster. Our present computational studies provide the electronic structure and the optical spectra of the dye- $\mathrm{TiO}_{2}$ nanocluster system. We analyze various binding configurations of the dye to the cluster and discuss the energy level alignment with the semiconducting oxide and the electrolyte as well as the charge transfer from the pigment to the oxide. We compare our theoretical results with the experimental data available and explain the puzzling behavior of the short-circuit current.

\section{Computational Details}

The structures of all dyes were optimized in their various forms, including protonated and/or deprotonated correspondents, using the density functional theory (DFT) [36-38], with the B3LYP exchange-correlation functional $[39,40]$ and the 6-31G(d) basis set [41] for the free dyes or the less demanding 3-21G(d) basis set for the adsorbed dyes on the anatase cluster model. Vibrational analysis was performed at the same level of theory to check the stability of all optimized structures and to obtain the zero-point corrections to the total electronic energies.

The molecular orbitals and electronic transitions were calculated in solvent (water) employing the polarizable continuum model (PCM) [42, 43], by TD-DFT [44] using the same B3LYP functional. The cavity used in the PCM calculation was built from spheres centered on heavy nuclei, 
based on the United Atom for Hartree-Fock procedure described in $[42,43]$. The basis sets on the heavier atoms were augmented by diffuse functions via $6-31+G(d)$ [41] for better evaluation of electronic states of the free dyes. In the case of the dyes adsorbed on the cluster, the electronic states were accurately computed using the double- $\zeta$ quality DZVP basis sets including polarization functions for the valence electrons [45]. All calculations were performed with the GAUSSIAN03 package [46].

\section{Results and Discussion}

This section is divided in five parts. The first two subsections refer to the independent dye, dealing with the proton affinity and the electron transfer. The third subsection treats the $\mathrm{TiO}_{2}$ nanocluster, whereas the last two deal with the more complex system consisting of the dye-oxide couple.

3.1. Dye Deprotonation. In a previous study [28] we reported extensive experimental and theoretical studies of DSSCs sensitized with Mordant Yellow 10, 5-(4-sulfophenylazo)salicylic acid disodium salt, $\mathrm{C}_{13} \mathrm{H}_{8} \mathrm{~N}_{2} \mathrm{Na}_{2} \mathrm{O}_{6}$ S. The dye has the structural pattern of salicylic acid, having three functional groups: one of them $\left(-\mathrm{SO}_{3}{ }^{-}\right)$ensures its solubility in water and the others $\left(-\mathrm{COO}^{-},-\mathrm{OH}\right)$ act as chelating groups. MY-10 may also be viewed as the product of the double deprotonation of an organic acid, 5-(4-sulfophenylazo)salicylic acid, which for convenience will be labeled here as $\mathrm{H}_{3} \mathrm{ACY}$ (acid chrome yellow). Consequently, we further label $\mathrm{H}_{2} \mathrm{ACY}^{-}, \mathrm{HACY}^{2-}$, and $\mathrm{ACY}^{3-}$, the various partially and fully deprotonated species.

One of the key factors required for an efficient operation of the DSSCs is the ability of the dye molecules to adsorb onto the semiconductor surface. This condition is uniquely fulfilled by $\mathrm{H}_{3} \mathrm{ACY}$, which offers the ground for comparing some of the most important anchoring groups: $-\mathrm{COOH}$, $-\mathrm{OH}$, and $-\mathrm{SO}_{3} \mathrm{H}$, all present in the same simple pigment. Upon adsorption of the dye on the substrate, the proton of the anchoring group is lost by the pigment. In order to identify the most probable deprotonation site, and thus which group is energetically favored to act as anchor, we computed the proton affinities of the dyes, in water solvent, as energy difference between the various deprotonated species and the protonated form.

The deprotonation of $\mathrm{H}_{3} \mathrm{ACY}$ was performed at sites labeled as H1, H2, and H3 in Figure 1. Vibration analysis was performed on all optimized structures to ensure their stable character and to provide zero-point corrections to proton affinities. The results are presented in Table 1.

Based on the results shown in Table 1, the first proton to go is $\mathrm{H1}$, the one that belongs to the $-\mathrm{SO}_{3} \mathrm{H}$ group. The energy required for the deprotonation increases for the hydroxyl group and even more so for the carboxyl group. However, the deprotonation at the $\mathrm{H} 2$ and $\mathrm{H} 3$ sites is almost as likely to occur, the difference in energy being very small.

Considering next the double deprotonation, we note that once the first proton is gone from the sulfonic group, the next proton that can leave the molecule is at the $-\mathrm{OH}$ group. Again, the difference in energy being so small, it is almost as

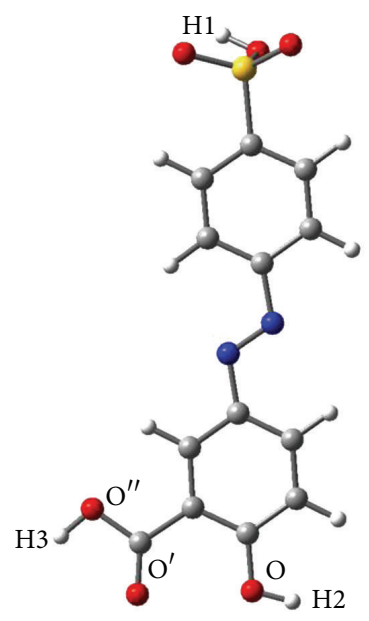

FIGURE 1: Optimized geometry of the dye, in its protonated form, as acid chrome yellow $\left(\mathrm{H}_{3} \mathrm{ACY}\right)$, calculated at DFT/B3LYP/6-31G(d) level. The atom labeling is used in Table 1.

TABLE 1: Proton affinities (PA) of H3ACY in water solution using the PCM approach $[42,43]$.

\begin{tabular}{lcc}
\hline Dye (deprotonation site) & $\begin{array}{c}\text { Energy } \\
\text { (hartree) }\end{array}$ & $\begin{array}{c}\text { Proton } \\
\text { affinity }(\mathrm{eV})\end{array}$ \\
\hline $\begin{array}{l}\mathrm{ACY} \\
\text { and H3) }\end{array}$ & -1459.0783688 & 36.97 \\
$\mathrm{H}^{3-} \mathrm{ACY}^{2-}$ (missing H2 and H3) & -1459.5074405 & 25.29 \\
$\mathrm{H}_{2}-\mathrm{ACY}^{2-}$ (missing H1 and H3) & -1459.5449373 & 24.27 \\
$\mathrm{H} 3-\mathrm{ACY}^{2-}$ (missing H1 and H2) & -1459.5473253 & 24.21 \\
$\mathrm{H} 1 \mathrm{H} 2-\mathrm{ACY}^{-}$(missing H3) & -1459.9751650 & 12.57 \\
$\mathrm{H} 1 \mathrm{H} 3-\mathrm{ACY}^{-}$(missing H2) & -1459.9792599 & 12.45 \\
$\mathrm{H} 2 \mathrm{H} 3-\mathrm{ACY}^{-}$(missing H1) & -1460.0061527 & 11.72 \\
$\mathrm{H}_{3} \mathrm{ACY}$ & -1460.4369320 & - \\
\hline
\end{tabular}

likely for the proton to leave the $-\mathrm{CO}_{2} \mathrm{H}$ group. Unlikely is the deprotonation at the hydroxyl and carboxyl groups leaving the proton on the sulfonic group. Finally, the loss of all three protons comes at a higher price.

3.2. Electron Transfer for the Free Dye. Based on the experimental and theoretical results reported in our earlier paper [28], we exclude the case of $\mathrm{ACY}^{3-}$, as it led to poor energy level alignment and small photovoltaic conversion efficiency. Also, the case of the fully protonated dye, $\mathrm{H}_{3} \mathrm{ACY}$, is not of real interest, as the binding to the substrate only through $\mathrm{H}$-bonds is unlikely $[15,21]$ and unappealing. As we shall demonstrate in Section 3.4, the H-bonds may strengthen mechanically the anchoring to the substrate when other binding pathways exist. However, in the absence of $\pi$ binding pathways, the presence of an intermediate $\mathrm{H}$ atom can harm the charge injection. It is the presence of conjugated bonds, allowing for $\pi$ electron delocalization, that facilitates the electron transfer [47].

We assume that the energy level alignment is appropriate, allowing for the electron injection into the conduction 


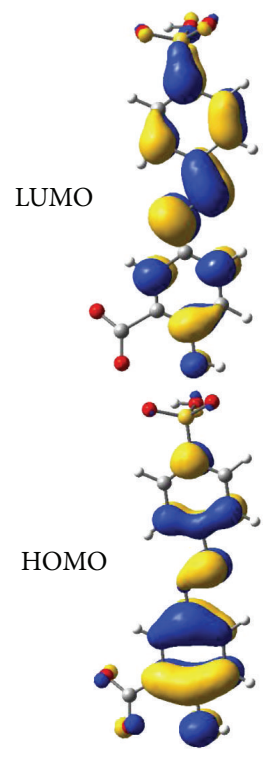

$\mathrm{H} 1 \mathrm{H} 2-\mathrm{ACY}^{-}$

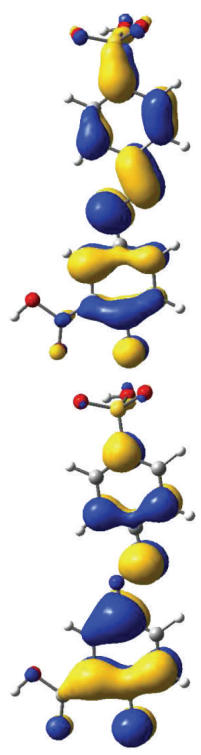

$\mathrm{H} 1 \mathrm{H} 3-\mathrm{ACY}^{-}$

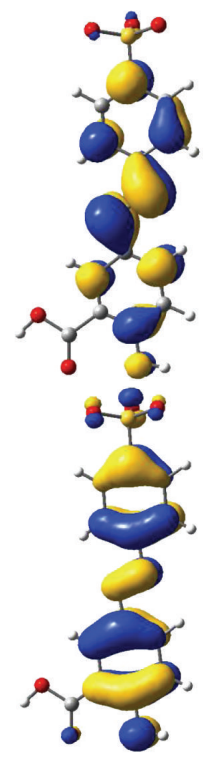

$\mathrm{H} 2 \mathrm{H} 3-\mathrm{ACY}^{-}$

FIGURE 2: Isodensity surfaces $\left(0.03 \mathrm{e} / \mathrm{bohr}^{3}\right)$ of the key molecular orbitals of the single deprotonated forms of the dye calculated at DFT/B3LYP/6-31+G(d) level in water.

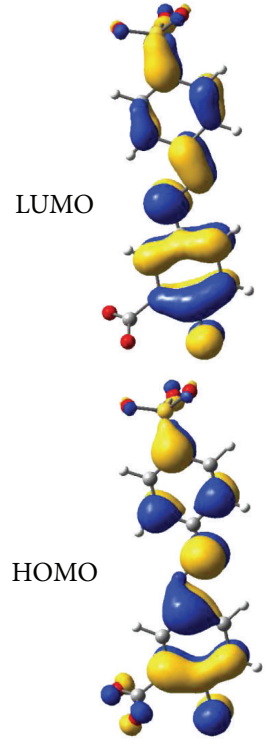

$\mathrm{H} 1-\mathrm{ACY}^{2-}$
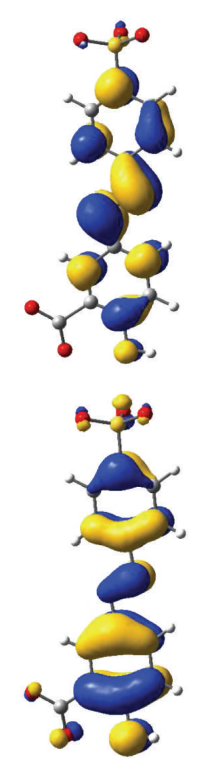

$\mathrm{H} 2-\mathrm{ACY}^{2-}$
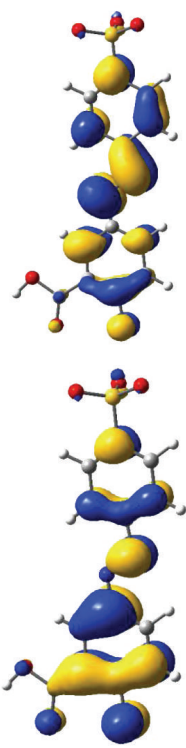

$\mathrm{H} 3-\mathrm{ACY}^{2-}$

Figure 3: Isodensity surfaces $\left(0.03 \mathrm{e} / \mathrm{bohr}^{3}\right)$ of the key molecular orbitals of the double deprotonated forms of the dye calculated at DFT/B3LYP/6-31+G(d) level in water.

band of the oxide, and the regeneration of the sensitizer is possible. This requirement is verified by the single and double deprotonated forms of the dye, as shown earlier for two particular cases [28]. To also explore the likelihood of the electron transfer processes, it is useful to also look at the electron densities of the highest occupied (HO) and lowest unoccupied (LU) molecular orbitals (MO) of the single and double deprotonated forms of the dye (see Figures 2 and 3, resp.). A quantitative measure of the propensity for electron transfer of the dyes can be obtained by calculating the contribution to the electron density of each atom and adding these weights for three units, considered as donor, bridge, and acceptor. The three distinct units that we considered are benzenesulfonic acid, azo group, and salicylic acid. The values are reported in Table 2.

As it can be seen in Figures 2 and 3, the azo group plays an important role in the molecule as the nature of the bonding between the two nitrogen atoms correlates 
TABLE 2: Contributions of various groups, in \%, to the electron density of the HOMO and LUMO, calculated at DFT/B3LYP/6-31+G(d) level.

\begin{tabular}{|c|c|c|c|c|}
\hline Dye & MO & BSA & $-\mathrm{N}=\mathrm{N}-$ & SA \\
\hline \multirow{2}{*}{$\mathrm{H} 2-\mathrm{ACY}^{2-}$ (missing $\mathrm{H} 1$ and $\mathrm{H} 3$ ) } & HOMO & 26.73 & 7.80 & 65.46 \\
\hline & LUMO & 33.96 & 38.52 & 27.51 \\
\hline \multirow{2}{*}{$\mathrm{H} 1 \mathrm{H} 2-\mathrm{ACY}^{-}$(missing H3) } & HOMO & 37.75 & 7.84 & 54.41 \\
\hline & LUMO & 52.70 & 19.93 & 27.37 \\
\hline \multirow{2}{*}{$\mathrm{H} 1-\mathrm{ACY}^{2-}$ (missing H2 and H3) } & HOMO & 49.81 & 6.72 & 43.47 \\
\hline & LUMO & 46.20 & 7.20 & 46.60 \\
\hline \multirow{2}{*}{$\mathrm{H} 3-\mathrm{ACY}^{2-}$ (missing $\mathrm{H} 1$ and $\mathrm{H} 2$ ) } & HOMO & 49.80 & 6.72 & 43.48 \\
\hline & LUMO & 48.43 & 11.27 & 40.30 \\
\hline \multirow{2}{*}{$\mathrm{H} 1 \mathrm{H} 3-\mathrm{ACY}^{-}$(missing H2) } & HOMO & 44.46 & 11.53 & 44.01 \\
\hline & LUMO & 53.20 & 21.18 & 25.62 \\
\hline \multirow{2}{*}{$\mathrm{H} 2 \mathrm{H} 3-\mathrm{ACY}^{-}$(missing $\mathrm{H} 1$ ) } & HOMO & 38.24 & 11.49 & 50.27 \\
\hline & LUMO & 38.42 & 38.08 & 23.49 \\
\hline
\end{tabular}

BSA: benzenesulfonic acid, SA: salicylic acid.

well with the character of the entire molecular orbital. The $\mathrm{HOMO}$ is an $\pi$ orbital and corresponds to an $-\mathrm{N}=\mathrm{N}-$ double bound, whereas the LUMO is an $\pi^{*}$ orbital, matching the antibonding between the nitrogen atoms.

The propensity for electron transfer of the dyes can be correlated with the variation in electron density following the photoexcitation of the dye from the ground to the excited state. The push-pull concept [11] expresses the tendency of a donating part of the dye to transfer an electron, through an $\pi$ bridge, to an accepting unit.

In this context, looking at the values reported in Table 2, we note that for all forms of dye, the azo group has a higher electron density in the LUMO than in the HOMO. This increase comes from the decrease of electron density on the salicylic acid, with only one exception, $\mathrm{H} 1-\mathrm{ACY}^{2-}$, for which the variation is in case very small. Therefore, with one exception, when it is a very poor acceptor, the salicylic acid tends to act like an electron donor.

Looking carefully at the benzenesulfonic acid, we observe that it acts as a poor donor in the case of $\mathrm{H} 1-\mathrm{ACY}^{2-}$ and $\mathrm{H} 3-$ $\mathrm{ACY}^{2-}$. More often it tends to be an acceptor, a poor one in the case of $\mathrm{H} 2 \mathrm{H} 3-\mathrm{ACY}^{2-}$ and a much better one in the other instances, particularly for $\mathrm{H} 1 \mathrm{H} 2-\mathrm{ACY}^{2-}$.

The electron transfer from the dye to the oxide also depends on the matrix element connecting the two states [48], which is correlated with the orbital overlap between the $\pi^{*}$ orbital of the dye and the $d$ orbitals of the Ti(IV) ion [49]. In turn, the overlap depends on the relative symmetry of the orbitals and on the electron density localized on the binding atoms [17]. Qualitatively, the electron density of the key atoms can be seen in Figures 2 and 3. However, for a more quantitative approach, we display in Table 3 the electron density on the key oxygen atoms from the -OH group, the $\mathrm{COOH}$ group (the one situated closer to the hydroxyl group), and from the $-\mathrm{SO}_{3} \mathrm{H}$ group (considered all together).

As it can be seen from Table 3, the electron density is consistently high on the oxygen atom of the $-\mathrm{OH}$ group for the HOMOs of all forms of dye. In the case of the LUMOs there are some significant variations between the various dye species, the electron density being slightly larger than for the
HOMO of H1-ACY ${ }^{2-}$ but significantly smaller in the rest. This result suggests that if the dye binds to the titania substrate through the oxygen of the $-\mathrm{OH}$ group, the higher electron transfer rate would occur in the case of the H1-ACY ${ }^{2-}$ dye.

The oxygen atom on the $-\mathrm{COOH}$ group has, consistently, a smaller electron density than the oxygen of the $-\mathrm{OH}$ group, for all the key MOs. These small values of the electron densities on the $-\mathrm{COOH}$ suggest that, if the binding was through that oxygen atom, the electron injection rate would be relatively low. The two cases for which the electron density is more significant are when the $\mathrm{H} 3$ proton is present, $\mathrm{H} 3$ $\mathrm{ACY}^{2-}$ and $\mathrm{H} 1 \mathrm{H} 3-\mathrm{ACY}^{-}$, but even in these instances, the LUMOs have lower charge than the corresponding HOMOs. Therefore, if the dye binds to the titania substrate through the oxygen of the $-\mathrm{COOH}$ group, one would expect a relatively low transfer rate.

The electron density present on the three oxygen atoms of the sulfonic group is smaller or comparable to the one localized on the hydroxyl group. However, the charge is slightly larger in the LUMOs of the single deprotonated dyes that preserve the $\mathrm{H} 1$ proton: $\mathrm{H} 1 \mathrm{H} 2-\mathrm{ACY}^{-}$and $\mathrm{H} 1 \mathrm{H} 3-\mathrm{ACY}^{-}$. The charge increases from HOMO to LUMO in the cases when the $\mathrm{H} 1$ proton is present, but in such cases, the binding to the titania cluster would be hindered. Hence, we are led to think that if the dye binds through the sulfonic group, the electron transfer rate would be relatively small.

To summarize the analysis of this section, none of the forms of the dye is optimized for the use in DSSCs, as the push-pull effects and the charge on the binding atoms are far from being competitive. However, these systems provide an interesting laboratory for the analysis of some of the key DSSC sensitizer design criteria. Taking each form of dye one by one, based on the limited information provided by Tables 2 and 3, we can speculate the following:

(i) $\mathrm{H} 1-\mathrm{ACY}^{2-}$ : there is a slight push-pull effect from the benzenesulfonic acid to the azo bridge and the salicylic acid, and the electron density on the peripheral oxygen atom is high. Binding through the oxygen of the $-\mathrm{OH}$ group might lead to a sizeable electron transfer; 
TABLE 3: Contributions of the oxygen atoms ( $\mathrm{O}$ from the $-\mathrm{OH}$ group, $\mathrm{O}^{\prime}$ from the $-\mathrm{COOH}$ group, and all from the $-\mathrm{SO}_{3} \mathrm{H}$ group, considered together), in \%, to the electron density of the HOMO and LUMO, calculated at DFT/B3LYP/6-31+G(d) level.

\begin{tabular}{|c|c|c|c|c|}
\hline Dye & $\mathrm{MO}$ & $\mathrm{O}(-\mathrm{OH})$ & $\mathrm{O}^{\prime}(-\mathrm{COOH})$ & $3 \times \mathrm{O}\left(-\mathrm{SO}_{3} \mathrm{H}\right)$ \\
\hline \multirow{2}{*}{$\mathrm{H} 2-\mathrm{ACY}^{2-}$ (missing $\mathrm{H} 1$ and $\mathrm{H} 3$ ) } & HOMO & 9.48 & 0.99 & 1.82 \\
\hline & LUMO & 1.99 & 0.02 & 1.67 \\
\hline \multirow{2}{*}{$\mathrm{H} 1 \mathrm{H} 2-\mathrm{ACY}^{-}$(missing H3) } & HOMO & 8.21 & 0.84 & 0.89 \\
\hline & LUMO & 1.40 & 0.01 & 2.31 \\
\hline \multirow{2}{*}{$\mathrm{H} 1-\mathrm{ACY}^{2-}$ (missing H2 and H3) } & HOMO & 3.28 & 0.65 & 1.07 \\
\hline & LUMO & 3.75 & 0.08 & 2.49 \\
\hline \multirow{2}{*}{$\mathrm{H} 3-\mathrm{ACY}^{2-}$ (missing $\mathrm{H} 1$ and $\mathrm{H} 2$ ) } & HOMO & 14.05 & 6.62 & 1.34 \\
\hline & LUMO & 3.11 & 0.40 & 1.33 \\
\hline \multirow{2}{*}{ H1H3-ACY ${ }^{-}$(missing H2) } & HOMO & 8.86 & 1.37 & 1.22 \\
\hline & LUMO & 3.20 & 0.47 & 3.52 \\
\hline \multirow{2}{*}{$\mathrm{H} 2 \mathrm{H} 3-\mathrm{ACY}^{-}$(missing H1) } & HOMO & 10.33 & 0.87 & 4.29 \\
\hline & LUMO & 2.20 & 0.07 & 1.58 \\
\hline
\end{tabular}

(ii) $\mathrm{H} 2-\mathrm{ACY}^{2-}$ : there is a clear push effect from the salicylic group, but the charge remains localized on the azo group, with a slight pull effect from the benzenesulfonic acid. Under these circumstances, the transfer through the carboxyl group is likely to be small due to both the reverse push-pull and the small electron density. The binding through the sulfonic group might be advantageous due to the push-pull and the charge density on the peripheral oxygen atoms but remains questionable due to the symmetry of the binding orbitals;

(iii) $\mathrm{H} 3-\mathrm{ACY}^{2-}$ : both acids push the charge to the azo bridge group located in the middle of the molecule. Binding through the oxygen of the hydroxyl seems more desirable;

(iv) $\mathrm{H} 2 \mathrm{H} 3-\mathrm{ACY}^{-}$: fairly similar to $\mathrm{H} 3-\mathrm{ACY}^{2-}$;

(v) $\mathrm{H} 1 \mathrm{H} 2-\mathrm{ACY}^{-}$: there is a significant push-pull effect from the salicylic acid to the benzenesulfonic acid. The binding through the oxygen atoms of the sulfonic group seems more likely to allow for charge transfer (provided that) but the $\mathrm{H} 1$ proton may hinder such binding;

(vi) $\mathrm{H} 1 \mathrm{H} 3-\mathrm{ACY}^{-}$: a case relatively similar to $\mathrm{H} 1 \mathrm{H} 2-\mathrm{ACY}^{-}$.

3.3. Titania Nanocluster. $\mathrm{TiO}_{2}$ anatase nanoparticles are modeled by a geometry optimized cluster with the molecular formula $\mathrm{Ti}_{24} \mathrm{O}_{50} \mathrm{H}_{4}$, originating from the experimental structure of (101) surface, which is most common in the anatase form of $\mathrm{TiO}_{2}$ [50]. To avoid the problem of the surface states in the gap, we performed geometry optimization of model clusters with a slight deviation from the $\mathrm{TiO}_{2}$ stoichiometry and introduced four hydrogen atoms to terminate the dangling bonds at the periphery. This approach resulted in compact structures with 4-, 5-, and 6-fold coordinated $\mathrm{Ti}$ ions, together with 2- and 3-fold coordinated oxygen atoms.

Following the geometry optimization, the structure is slightly distorted (see Figure 4) to minimize the surface stresses. Other clusters of larger sizes have also been studied

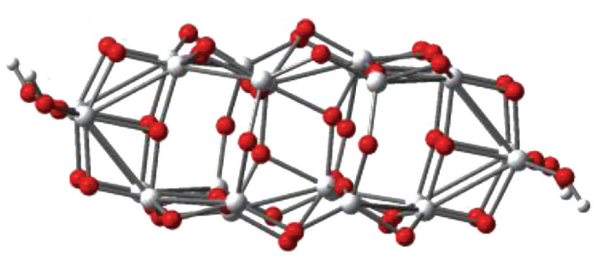

FIGURE 4: Lateral view of the optimized structures of the $\mathrm{Ti}_{24} \mathrm{O}_{50} \mathrm{H}_{4}$ nanocluster modeling the anatase titania (101) surface. The geometry optimization was performed at DFT/B3LYP/3-21G(d) level.

[51] but when dealing with relatively small molecules, such as MY-10, the $\mathrm{Ti}_{24} \mathrm{O}_{50} \mathrm{H}_{4}$ cluster provides a reasonable compromise between accuracy and computational costs. Larger clusters, such as $\left(\mathrm{TiO}_{2}\right)_{82}$, might be more appropriate when dealing with larger dye molecules, particularly the typical ruthenium(II) complexes [52].

The average value of the Ti-O distance was $1.909 \AA$, smaller than the experimental value of $1.950 \AA$, valid for the bulk oxide. The distribution of these distances widens significantly compared to the bulk, with the standard deviation of the Ti-O distance being $0.133 \AA$ for the cluster and $0.022 \AA$ for the bulk. The deformation of the structure changes angles and distances such that the increase in the length of the cluster from $12.04 \AA$ in the bulk to $12.12 \AA$ in the cluster is opposite to the decrease in width, from $7.59 \AA$ to $7.21 \AA$. The relative variation of the cluster distances compared to the values in the bulk, is less than $5 \%$. We note that the values reported earlier [51] have slight deviations from those presented here, due to the different DFT functional and basis set used.

The geometry relaxation led to band gaps of $4.24 \mathrm{eV}$ significantly larger than the experimental value of $\sim 3.2 \mathrm{eV}$ for anatase titania [1]. We modeled $\mathrm{TiO}_{2}$ anatase nanoparticles by means of geometry-optimized clusters with molecular formulae $\mathrm{Ti}_{24} \mathrm{O}_{50} \mathrm{H}_{4}, \mathrm{Ti}_{34} \mathrm{O}_{70} \mathrm{H}_{4}$, and $\mathrm{Ti}_{44} \mathrm{O}_{90} \mathrm{H}_{4}$. [51]. The resulting bandgaps were $4.24,4.36$, and $4.26 \mathrm{eV}$, respectively, sensitive to the DFT functional and basis sets used. The differences from the experimental value of the bulk are likely due to the size effects, demonstrated [53] for $\left(\mathrm{TiO}_{2}\right)_{n}$ (with $n$ 


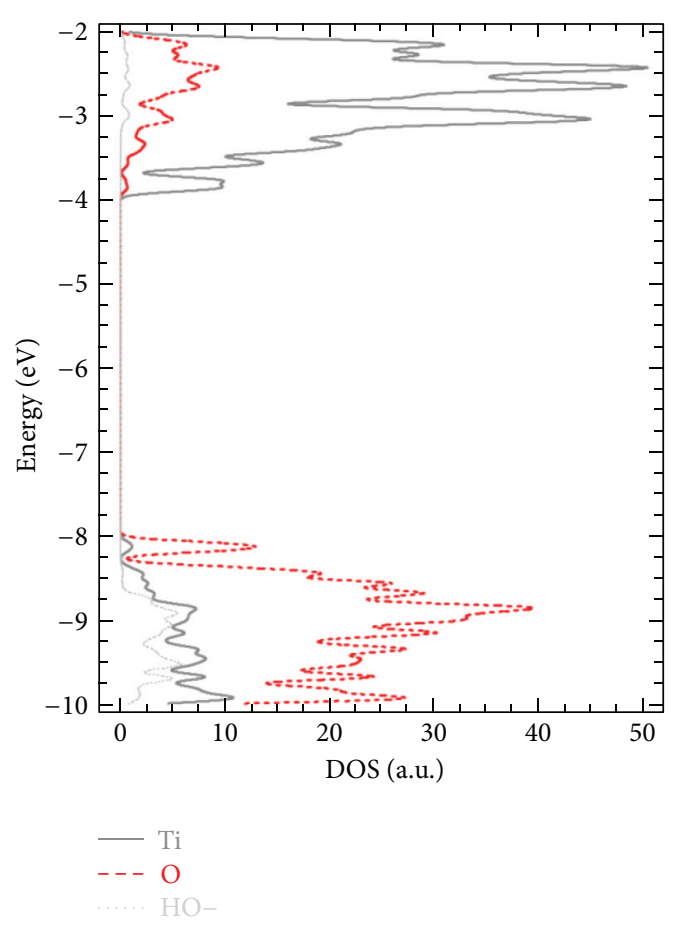

Figure 5: Density of states of the $\mathrm{Ti}_{24} \mathrm{O}_{50} \mathrm{H}_{4}$ cluster calculated at DFT/B3LYP/DZVP level in water. The contributions of the orbitals to $\mathrm{Ti}$ and $\mathrm{O}$ atoms as well as to the $-\mathrm{OH}$ groups are shown separately.

being between 1 and 68). Moreover, for $n<60$, the bandgap has a nonmonotonous variation with $n$ [53].

A quantity that crucially influences the performance of DSSCs is the position of the conduction band edge, which can be determined by DFT calculations, $E_{\mathrm{CB}}$, or based on the energy of the electronic transition, as an oxidation potential [35], CBOP: $-4.62 \mathrm{eV}$.

The nature of the states in the valence and conduction band can be more easily identified from Figure 4, which displays the density of states (DOS), and Figure 5, which illustrates the electron density of the key molecular orbitals. The valence band is dominated by the contributions from the $\mathrm{O} p$ orbitals, whereas the conduction band is dominated by the $d$ orbitals of the $\mathrm{Ti}$ atoms. The introduction of the hydrogen atoms that end the four dangling bonds has a minor contribution to the key regions of the DOS (near the edges of the valence and particularly conduction bands) but plays an important role in removing any surface states from the gap.

The electronic structure of the $\mathrm{Ti}_{24} \mathrm{O}_{50} \mathrm{H}_{4}$ cluster is shown in Figure 6. The highest occupied valence band (VB) state consists mostly of oxygen $2 p$ atomic orbitals, whereas the lowest unoccupied state of the conduction band is formed by titanium $3 d$ atomic orbitals.

3.4. Dye Adsorption: Binding Configurations. The anchoring modes of the dye to the $\mathrm{TiO}_{2}$ surface are of crucial importance, the bonding type and the extent of electronic coupling between the dye excited state and the semiconductor unoccupied states influencing directly the overall cell performance
TABLE 4: Distances, in $\AA$, and angles, in ${ }^{\circ}$, relevant to the binding through the $-\mathrm{COOH}$ group of the dye to the nanocluster. The geometry was optimized at DFT/B3LYP/3-21G(d) level.

\begin{tabular}{lcc}
\hline & $\mathrm{H} 2-\mathrm{ACY}^{2-}$ & $\mathrm{H} 1 \mathrm{H} 2-\mathrm{ACY}^{-}$ \\
\hline$r(\mathrm{Ti}-\mathrm{O})$ & 1.949 & 1.980 \\
$r\left(\mathrm{Ti}-\mathrm{O}^{\prime}\right)$ & 2.038 & 2.059 \\
$\psi$ & 39.10 & 32.41 \\
$\theta$ & 13.14 & 8.82 \\
$\varphi$ & -4.31 & -3.83 \\
\hline
\end{tabular}

$[1,4,30]$. As discussed in the Introduction, a number of theoretical studies have approached the adsorption of the dye on the titania surface $[5,29-33,51]$. The calculations show that for the organic dyes bearing a carboxylic acid as anchoring group, the preferred adsorption mode is bidentate bridging, with one proton transferred to a nearby surface oxygen, while the monodentate anchoring is usually predicted to be less stable [52].

In contrast to the usual dyes, MY-10 provides an unusually rich ground for exploration of the various binding configurations, as it offers $-\mathrm{SO}_{3} \mathrm{H},-\mathrm{COOH}$, and $-\mathrm{OH}$ anchoring groups. We start our analysis with the dyes anchored to the substrate in the familiar way, through the carboxyl group. The optimized geometries are shown in Figure 7 whereas the distances and angles relevant to the binding of the dye to the $\mathrm{Ti}_{24} \mathrm{O}_{50} \mathrm{H}_{4}$ cluster are presented in Table 4 .

In Table 4 , the angle $\psi$ was chosen between the dye axis (the direction joining the $\mathrm{S}$ atom and the $\mathrm{C}$ atom bound to the hydroxyl group) and the direction of the two binding $\mathrm{Ti}$ atoms. This way, the angle $\psi$ is sensitive to the difference between the two bond lengths and correlates to the mechanical strength of the anchoring of the dye to the substrate. The angle $\theta$ is made by the plane of the dye with the direction of the Ti-O bond. Finally, the angle $\varphi$ is measured between the plane of the dye and the direction defined by the two titanium ions bound to the dye. Both $\theta$ and $\varphi$ angles affect the orbital overlap between the $\pi^{*}$ of the dye and the $d$ orbitals of the $\mathrm{Ti}(\mathrm{IV})$ ion, influencing the electron transfer.

The first thing to note for both the $\mathrm{H} 1 \mathrm{H} 2-\mathrm{ACY}^{-}$and the $\mathrm{H} 2-\mathrm{ACY}^{2-}$ dyes is the bidentate bridging binding configuration, in agreement with other reports, either experimental [14-21] or theoretical $[29,30]$ for dyes with carboxyl group anchors. It is worth mentioning that starting the optimization from other initial geometries (monodentate ester-like or bidentate chelating) eventually leads to the same bidentate bridging configuration.

The two Ti-O bond lengths are different by less than $5 \%$ for both dyes. The shorter distances suggest a stronger binding for $\mathrm{H} 2-\mathrm{ACY}^{2-}$. The angle $\psi$ is well correlated with the relative difference between the $\mathrm{Ti}-\mathrm{O}$ distances, being larger for $\mathrm{H} 2-\mathrm{ACY}^{2-}$. The small values for the $\theta$ and $\varphi$ angles may suggest a weaker orbital overlap with the $d_{z 2}$ and a stronger overlap with $d_{x z}$.

We continue our analysis with the dyes anchored to the substrate, through the hydroxyl group. The optimized geometries are displayed in Figure 8. The bond lengths and 


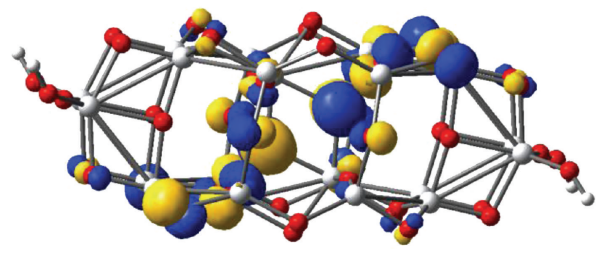

(a)

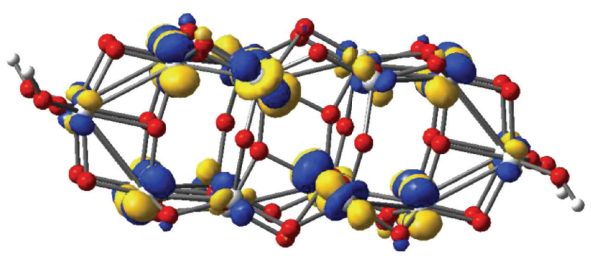

(b)

FIGURE 6: Isodensity surfaces $\left(0.03 \mathrm{e} / \mathrm{bohr}^{3}\right)$ of the key molecular orbitals of the $\mathrm{Ti}_{24} \mathrm{O}_{50} \mathrm{H}_{4}$ cluster, calculated at DFT/B3LYP/DZVP level in water: (a) highest occupied valence band orbital, (b) lowest unoccupied conduction band orbital.

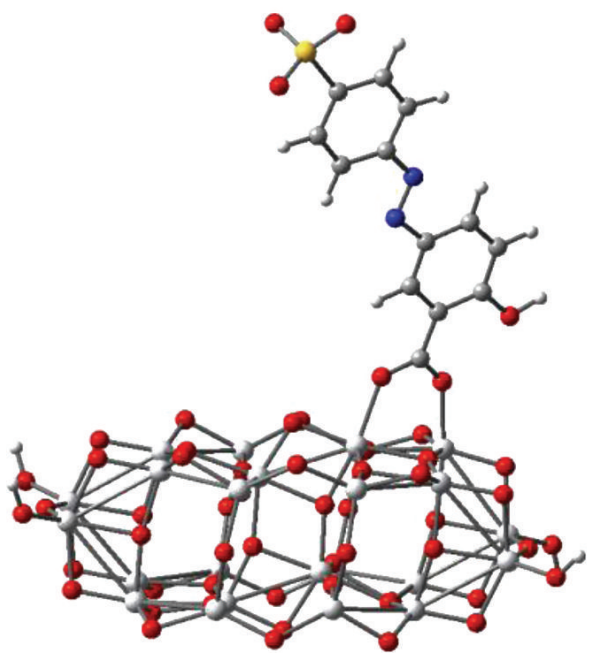

$\mathrm{H} 2-\mathrm{ACY}^{2-}$

(a)

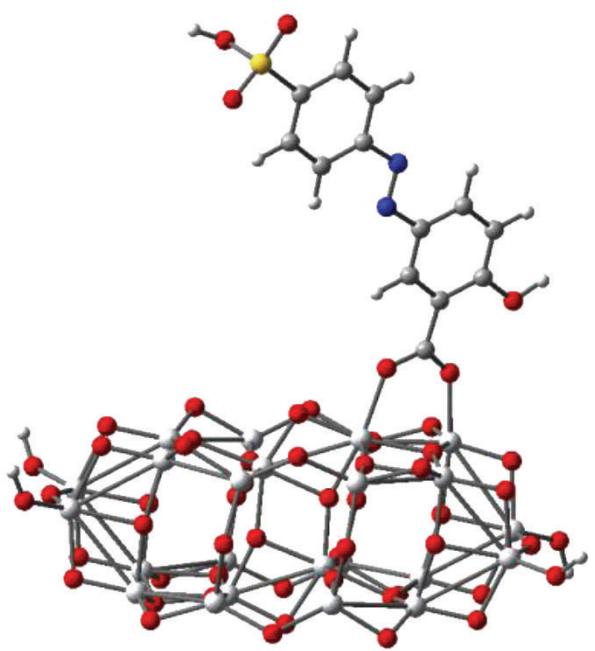

$\mathrm{H} 1 \mathrm{H} 2-\mathrm{ACY}^{-}$

(b)

FIGURE 7: Optimized structure of complex dye-oxide systems with anchoring through the carboxyl group, calculated at DFT/B3LYP/3-21G(d) level.

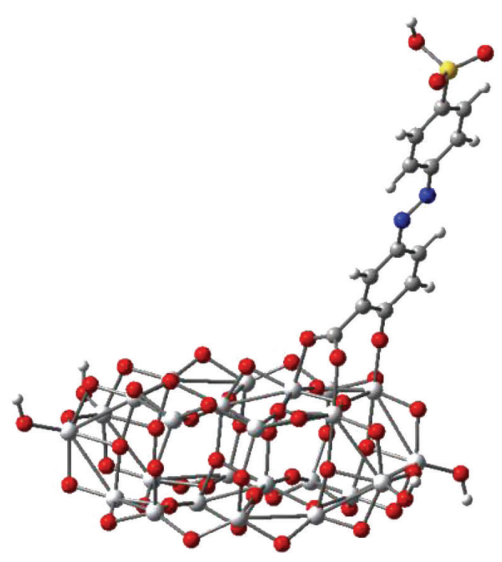

$\mathrm{H} 1-\mathrm{ACY}^{2-}$

(a)

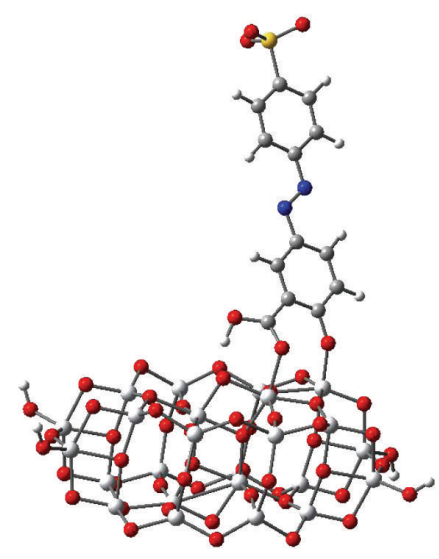

$\mathrm{H} 3-\mathrm{ACY}^{2-}$

(b)

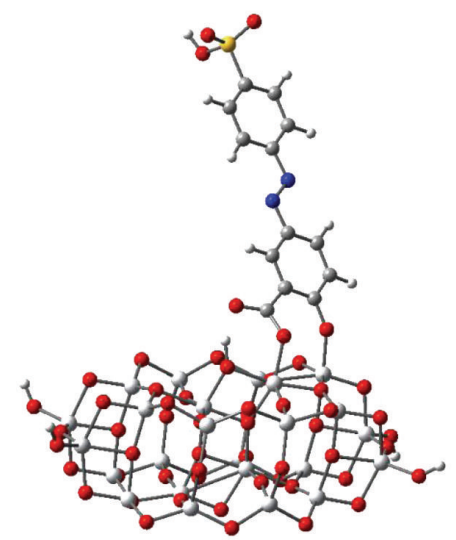

$\mathrm{H} 1 \mathrm{H} 3-\mathrm{ACY}^{-}$

(c)

FIGURE 8: Optimized structure of complex dye-oxide systems with anchoring primarily through the hydroxyl group, calculated at DFT/B3LYP/3-21G(d) level. 
TABle 5: Distances, in $\AA$, and angles, in ${ }^{\circ}$, relevant to the binding primarily through the $-\mathrm{OH}$ group of the dye to the nanocluster. $\mathrm{O}_{\mathrm{D}^{-}}$ $\mathrm{H}$ and $\mathrm{H}-\mathrm{O}_{\mathrm{S}}$ refer to the distances between the $\mathrm{H} 3$ proton and the adjacent oxygen atom on the dye and on the substrate, respectively. The geometry was optimized at DFT/B3LYP/3-21G(d) level.

\begin{tabular}{lccc}
\hline & $\mathrm{H}^{-}-\mathrm{ACY}^{2-}$ & $\mathrm{H}^{-}-\mathrm{ACY}^{2-}$ & $\mathrm{H} 1 \mathrm{H} 3-\mathrm{ACY}^{-}$ \\
\hline$r(\mathrm{Ti}-\mathrm{O})$ & 1.880 & 1.832 & 1.855 \\
$r\left(\mathrm{Ti}-\mathrm{O}^{\prime}\right)$ & 2.063 & 2.020 & 1.932 \\
$r\left(\mathrm{Ti}-\mathrm{O}^{\prime \prime}\right)$ & 2.029 & - & - \\
$r\left(\mathrm{O}_{\mathrm{D}}-\mathrm{H}\right)$ & - & 1.082 & 1.504 \\
$r\left(\mathrm{H}-\mathrm{O}_{\mathrm{S}}\right)$ & - & 1.462 & 1.060 \\
$\psi$ & 89.54 & 95.17 & 92.49 \\
$\theta$ & 16.96 & 29.35 & 33.58 \\
$\varphi$ & 28.12 & 11.53 & 10.45 \\
\hline
\end{tabular}

angles relevant to the binding of the dye to the nanocluster are reported in Table 5.

We note that for all three dyes, binding through the oxygen of the hydroxyl group is accompanied by supplementary binding through the adjacent carboxyl group. Also, for all three dyes, the shortest bond length is the one to the oxygen of the hydroxyl group, revealing the strongest bond. Moreover, the lengths of the shortest Ti-O bonds are smaller in this case than in the previous case of binding through a carboxyl anchor.

The similarities stop here as for the H1- $\mathrm{ACY}^{2-}$ dye, the binding is tridentate, through both oxygen atoms of $-\mathrm{COO}^{-}$. In this case, the group twists away from the plane of the dye allowing the two oxygen atoms to bind to the neighboring Ti(IV) ions. The axis of the dye suffers a large inclination, $\psi$, within its plane, while the plane of the pigment is rotated with respect to the Ti-Ti direction leading to a large $\varphi$ angle of $28.12^{\circ}$.

When the carboxyl group is protonated, the binding configuration remains bidentate, the difference arising from the supplementary hydrogen bond. In the case of $\mathrm{H} 3-\mathrm{ACY}^{2-}$ the proton remains bound in the carboxyl group, whereas for $\mathrm{H} 1 \mathrm{H} 3-\mathrm{ACY}^{-}$, the situation is reversed, the proton binding to an oxygen atom from the substrate. The large differences between the $\mathrm{O}-\mathrm{H}$ distances clearly show that in the latter case the proton leaves the dye and binds to the substrate. The value close to $90^{\circ}$ of $\theta$ in the case of $\mathrm{H1}-\mathrm{ACY}^{2-}$ suggests that that the dye is supported in a balanced way by its two pillars, the hydroxyl and the carboxyl groups. In the case of the other two dyes, $\mathrm{H} 3-\mathrm{ACY}^{2-}$ and $\mathrm{H} 1 \mathrm{H} 3-\mathrm{ACY}^{-}$, the values in excess of $90^{\circ}$ indicate that the axis is inclined due to shorter bond lengths with the oxygen of the hydroxyl group. Also, for these two pigments, the carboxyl group remains in the plane of the molecule, which suffers smaller deviations, $\varphi$, from the Ti-Ti direction.

The early work on surface complexation of colloidal titanium dioxide by various benzene derivatives $[25,26]$ suggested that the salicylate complex formed involves both substituent groups and leads to the formation of a six-atom ring with a chelating type of bonding to the same $\mathrm{Ti}(\mathrm{IV})$ ion (see Figure 9(a)). Our results confirm the involvement

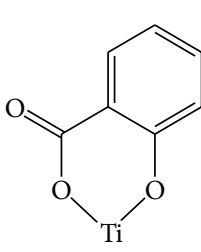

(a)

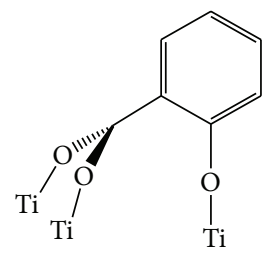

(b)

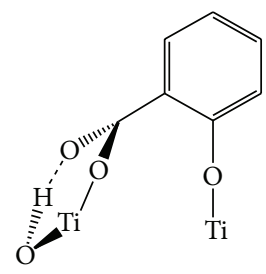

(c)
FIGURE 9: Binding schemes for the salycilate unit to the $\mathrm{TiO}_{2}$ substrate.

of both substituent groups but clearly demonstrate that the main binding configuration is bridging, engaging at least two adjacent titanium ions (Figures 9(b) and 9(c)). Moreover, a third bond, either a covalent O-Ti bond or a hydrogen bond, strengthens mechanically the anchoring to the substrate.

We end our analysis of the optimized geometry of the sensitizers adsorbed to the substrate with $\mathrm{H} 2 \mathrm{H} 3-\mathrm{ACY}^{-}$, for which the anchor is the sulfonic group. The optimized geometry is presented in Figure 10.

The geometry optimization of the complex system consisting of the $\mathrm{H} 2 \mathrm{H} 3-\mathrm{ACY}^{-}$sensitizer bound to the $\mathrm{Ti}_{24} \mathrm{O}_{50} \mathrm{H}_{4}$ cluster through the sulfonic group indicates tridentate binding to three adjacent $\mathrm{Ti}(\mathrm{IV})$ ions. The bond lengths are different, $2.155,2.167$, and $2.152 \AA$, longer than the typical values obtained in the previous cases. The angle $\psi$ is $83.21^{\circ}$, showing that the dye is not supported in a balanced way by its three pillars. The other angles are $\theta=13.75^{\circ}$ and $\varphi=6.26^{\circ}$, indicating a relatively small tilt of the plan of the dye with respect to the direction of the shortest Ti-O bond and also a fairly small rotation of that plan with respect to the Ti-Ti axis.

3.5. Electron Transfer for the Adsorbed Dye. In Section 3.2, we analyzed the propensity for charge transfer of the various free dyes. We return to the topic, this time treating the entire dye-substrate system. Following a similar procedure, we look at the key molecular orbitals, particularly at the one that corresponds to the excited state of the dye and the one that matches to the conduction band edge of the semiconductor.

As already mentioned, although the key information regarding the electron transfer rate may be provided by the matrix element connecting these two states [48], a simpler and still useful indication of the likelihood of the transfer may be offered by the overlap between the $\pi^{*}$ orbital of the dye and the $d$ orbitals of the Ti(IV) ion [49]. In turn, the overlap depends strongly on the electron density localized on the binding atoms. Qualitatively, the electron density of the key atoms can be seen in Figures 11 and 12, whereas some quantitative measures are reported in Tables 6 and 7, in the form of electron densities of the $\mathrm{TiO}_{2}$ nanocluster, on the entire dye as well as on its main three parts (benzenesulfonic acid, azo group, and salicylic acid), and on the peripheral oxygen atoms bound to titanium. The actual overlaps between the key orbitals involved in the charge transfer are reported in Table 8.

The key molecular orbitals of $\mathrm{H}_{2}-\mathrm{ACY}^{2-}$ and $\mathrm{H} 1 \mathrm{H} 2-$ $\mathrm{ACY}^{-}$are qualitatively similar in the sense that the HOMOs 


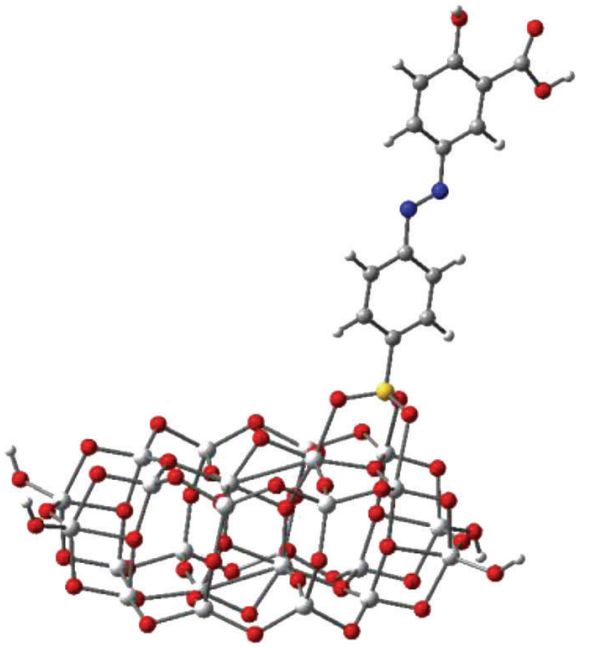

(a)

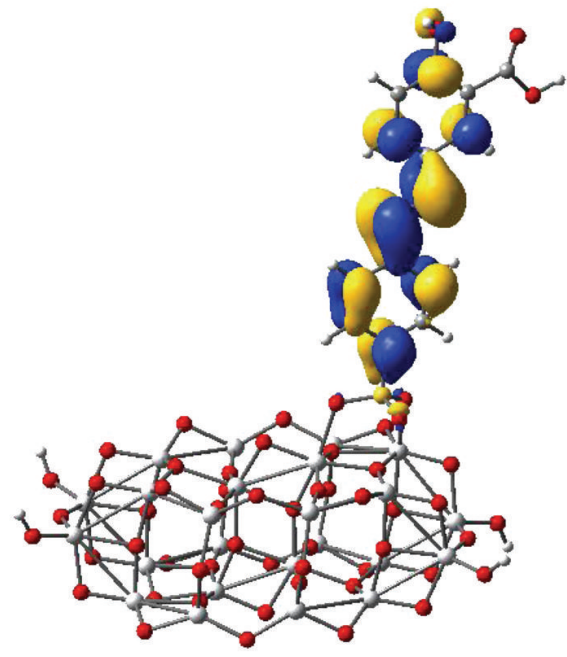

(b)

FIGURE 10: (a) Optimized structure of the $\mathrm{H} 2 \mathrm{H} 3-\mathrm{ACY}^{-}$-oxide system, with anchoring through the sulfonic group, calculated at DFT/B3LYP/3$21 \mathrm{G}$ (d) level. (b) Isodensity surfaces $\left(0.03 \mathrm{e} / \mathrm{bohr}^{3}\right)$ of the $\mathrm{MO}$ corresponding to the excited state of the sensitizer key molecular orbitals of the $\mathrm{H} 2 \mathrm{H} 3-\mathrm{ACY}^{-}$dye adsorbed on the $\mathrm{TiO}_{2}$ nanocluster calculated at DFT/B3LYP/DZVP level in water.

TABLE 6: Contributions of various groups, in \%, to the electron density of the $\mathrm{MO}$ corresponding to the excited state of the sensitizer, calculated at DFT/B3LYP/DZVP level.

\begin{tabular}{lcccccccc}
\hline Dye & $\mathrm{TiO}_{2}$ & Dye & BSA & $-\mathrm{N}=\mathrm{N}-$ & $\mathrm{SA}$ & $\mathrm{O}^{\prime}$ & $\mathrm{O}^{\prime \prime}$ & $\mathrm{O}$ \\
\hline $\mathrm{H} 2-\mathrm{ACY}^{2-}$ & 18.74 & 81.26 & 22.46 & 39.82 & 18.98 & 0.031 & 0.106 & 2.008 \\
$\mathrm{H} 1 \mathrm{H} 2-\mathrm{ACY}^{-}$ & 9.23 & 90.77 & 28.65 & 39.98 & 22.14 & 0.025 & 0.118 & 2.772 \\
\hline
\end{tabular}

BSA: benzenesulfonic acid, SA: salycilic acid.

and the LUMOs have $\pi$ and $d$ characters, respectively. Moreover, the HOMOs and LUMOs are strongly localized on the dye and on the substrate, respectively, whereas the MO corresponding to the excited state of the sensitizer has a mixed character, being delocalized also on the titania cluster.

When looking at the free $\mathrm{H} 2-\mathrm{ACY}^{2-}$ dye, we noticed a sizeable push effect from the salicylic group and a slight pull effect from the benzenesulfonic acid, with the charge localized on the azo group. In the case of the interacting sensitizer, binding through the carboxyl group, where the charge is negligible, leads to almost $19 \%$ delocalization of the electron over the substrate. The higher electron density on the oxygen of the hydroxyl group remains unused.

In the case of $\mathrm{H} 1 \mathrm{H} 2-\mathrm{ACY}^{-}$, there is a significant change between the noninteracting and the interacting sensitizers. In the free case, we found a clear push-pull effect from the salicylic to the benzenesulfonic acid but when the dye is adsorbed on the substrate, the charge tends to localize more on the azo group, and about $9 \%$ leaks to the cluster. Similar to the previous case, the charge on the carboxyl group is negligible and the high density on the hydroxyl group substrate stays trapped.

We now move further to the dyes bound through the oxygen of the hydroxyl group. The HOMOs and the LUMOs have, as expected, $\pi$ and $d$ characters, respectively, and are strongly localized on the dye or on the substrate. The MO
TABLE 7: Contributions of various groups, in \%, to the electron density of the HOMO and LUMO, calculated at DFT/B3LYP/DZVP level.

\begin{tabular}{lcccccccc}
\hline Dye & $\mathrm{TiO}_{2}$ & Dye & BSA & $-\mathrm{N}=\mathrm{N}-$ & $\mathrm{SA}$ & $\mathrm{O}^{\prime}$ & $\mathrm{O}^{\prime \prime}$ & $\mathrm{O}$ \\
\hline${\mathrm{H} 1-\mathrm{ACY}^{2-}}^{2-}$ & 29.37 & 70.63 & 21.43 & 30.21 & 18.99 & 0.042 & 0.133 & 0.830 \\
$\mathrm{H} 3-\mathrm{ACY}^{2-}$ & 70.83 & 29.17 & 6.58 & 12.32 & 10.28 & 0.256 & 0.194 & 0.280 \\
$\mathrm{H} 1 \mathrm{H} 3-\mathrm{ACY}^{-}$ & 79.42 & 20.58 & 5.05 & 7.70 & 7.83 & 0.084 & 0.521 & 0.211 \\
\hline
\end{tabular}

BSA: benzenesulfonic acid, SA: salycilic acid.

corresponding to the excited state of the sensitizer has a mixed character, being delocalized also on the titania cluster.

In the case of $\mathrm{H} 1-\mathrm{ACY}^{2-}$, almost $30 \%$ of the electron density is distributed over the cluster, whereas the percentages are significantly larger, for both $\mathrm{H} 3-\mathrm{ACY}^{2-}$ and $\mathrm{H} 1 \mathrm{H} 3-\mathrm{ACY}^{-}$, of more than $70 \%$ and $79 \%$, respectvely. The much larger charge distributed on the titania, reflecting the higher likelihood of charge transfer, may be correlated with the strong binding through both salycilate substituents. We note, as it can be seen from Figure 12, that the main pathway for charge transfer is through the oxygen atom of the hydroxyl group.

The free H1-ACY ${ }^{2-}$ dye showed a slight push-pull effect from the benzenesulfonic acid towards the azo bridge and the salycilic acid. Also, the electron density on the peripheral oxygen atom was high. The interacting dye tends, again, to accumulate more charge on the azo group but passes more of it to the substrate, by taking advantage of the higher orbital overlap.

In the case of the noninteracting $\mathrm{H} 3-\mathrm{ACY}^{2-}$ sensitizer, both acids push the charge to the azo bridge group located in the middle of the molecule, whereas the high electron density on the oxygen atom makes the binding through the corresponding hydroxyl more desirable. This tendency is preserved for the interacting sensitizer, whose electron density is 

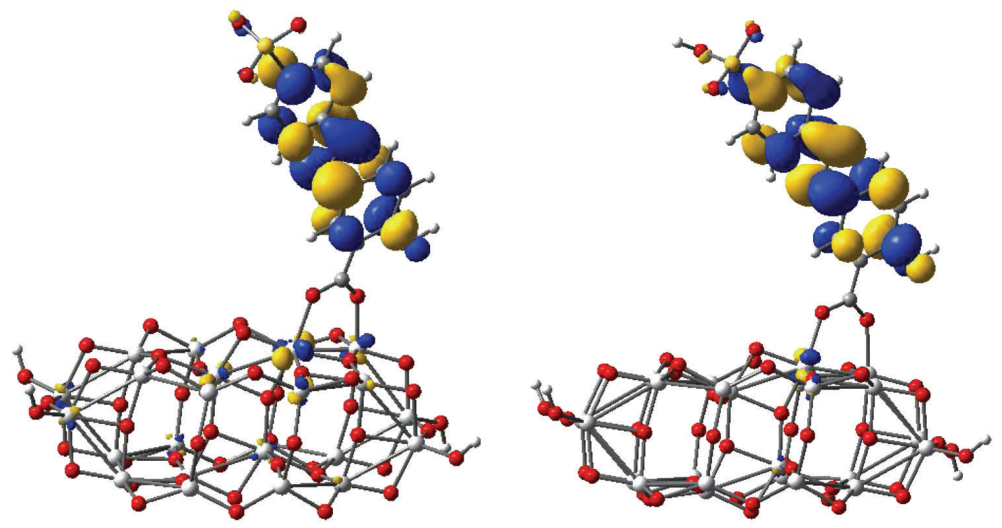

LUMO+9

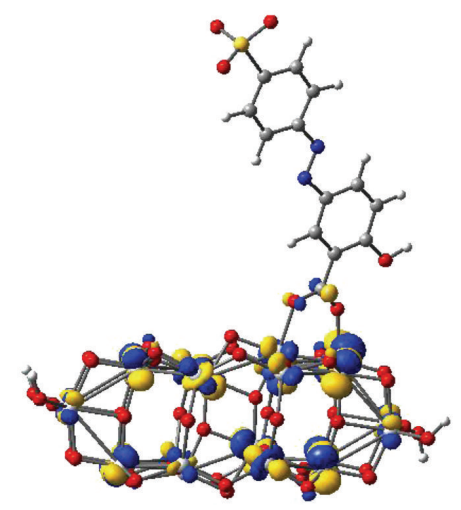

$\mathrm{LUMO}+4$

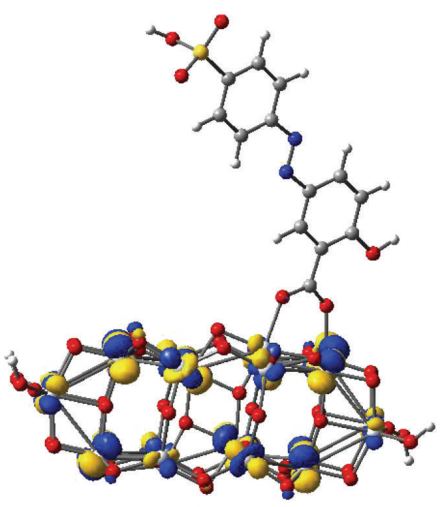

LUMO

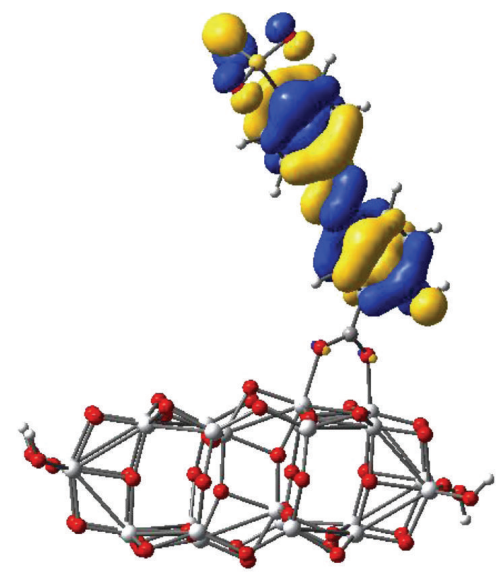

HOMO-1

$\mathrm{H} 2-\mathrm{ACY}^{2-}$

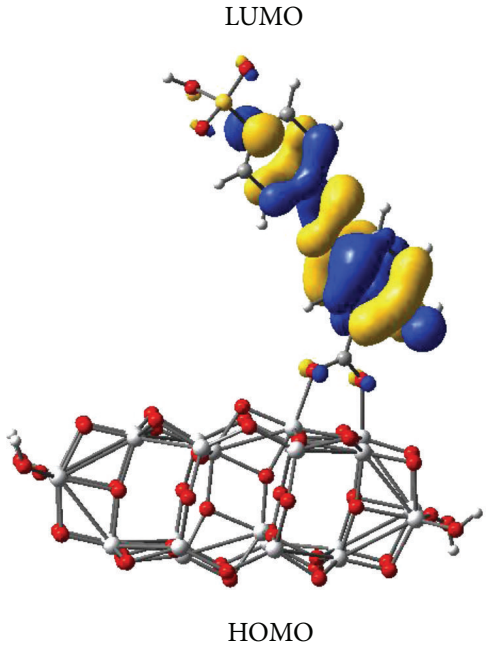

$\mathrm{H} 1 \mathrm{H} 2-\mathrm{ACY}^{-}$

Figure 11: Isodensity surfaces $\left(0.03 \mathrm{e} / \mathrm{bohr}^{3}\right)$ of the key molecular orbitals of the dyes adsorbed on the $\mathrm{TiO}_{2}$ nanocluster calculated at DFT/B3LYP/DZVP level in water.

now more significantly pushed from the benzenesulfonic acid through the median azo group towards the salicylic group and the substrate.

The single deprotonated dye $\mathrm{H} 1 \mathrm{H} 3-\mathrm{ACY}^{2-}$ displayed a clear push-pull effect from the salycilic to the benzenesulfonic acid, but when the pigment is adsorbed on the substrate the charge tends to transfer in the opposite direction towards the cluster.
We note for the last two dyes that the presence of the intermediate $\mathrm{H}$ atom does not create a significant pathway for charge injection, the $\mathrm{H}$-bonding having a more important role in the mechanical adherence to the oxide.

The orbital overlap between the MOs corresponding to the excited state of the dye and the conduction band edge of the substrate is correlated, as expected, with the electron densities on the peripheral, contact atoms. The overlap is 


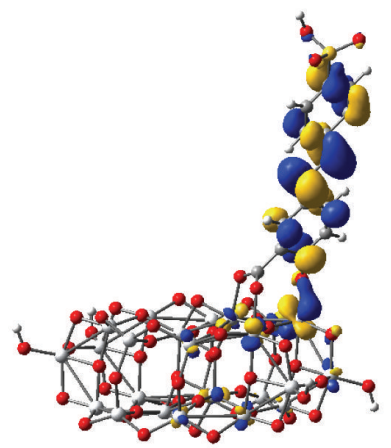

$\mathrm{LUMO}+2$

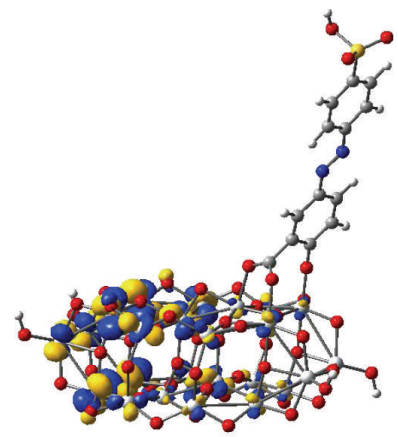

LUMO

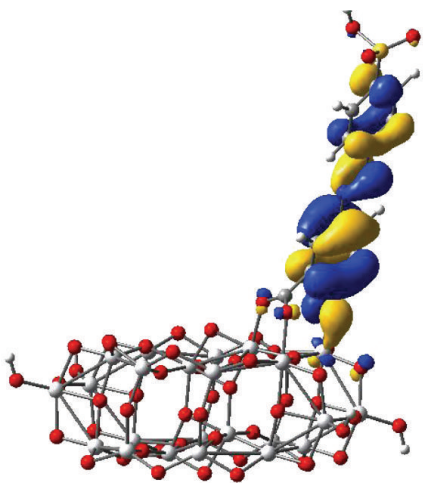

HOMO

$\mathrm{H} 1-\mathrm{ACY}^{2-}$

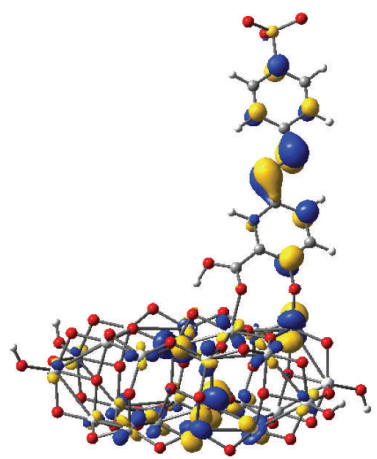

$\mathrm{LUMO}+4$

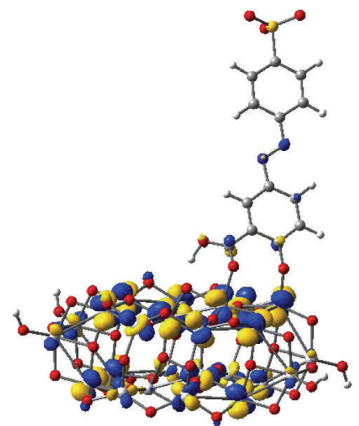

LUMO

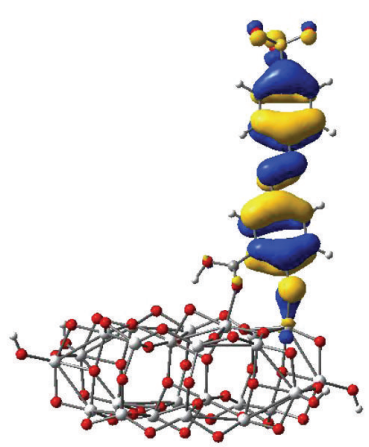

HOMO

$\mathrm{H} 3-\mathrm{ACY}^{2-}$

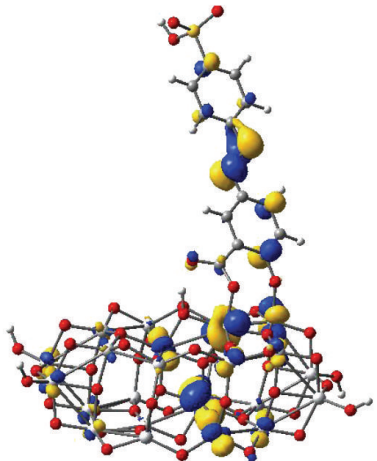

$\mathrm{LUMO}+3$

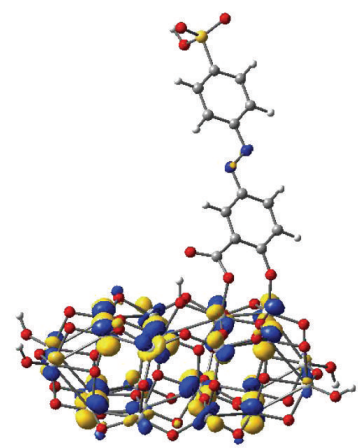

LUMO

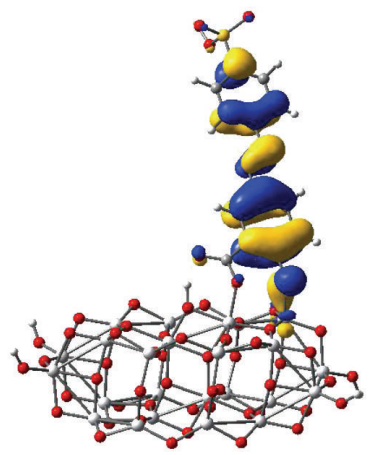

HOMO

$\mathrm{H} 1 \mathrm{H} 3-\mathrm{ACY}^{-}$

Figure 12: Isodensity surfaces $\left(0.03 \mathrm{e} / \mathrm{bohr}^{3}\right)$ of the key molecular orbitals of the dyes adsorbed on the $\mathrm{TiO}_{2}$ nanocluster calculated at DFT/B3LYP/DZVP level in water.

TABLE 8: Orbital overlap between the key molecular orbitals (the excited state of the dye and the conduction band edge of the substrate), calculated at DFT/B3LYP/DZVP level.

\begin{tabular}{|c|c|c|c|c|c|}
\hline $\mathrm{H} 2-\mathrm{ACY}^{2-}$ & $\mathrm{H} 1 \mathrm{H} 2-\mathrm{ACY}^{-}$ & $\mathrm{H} 1-\mathrm{ACY}^{2-}$ & $\mathrm{H} 3-\mathrm{ACY}^{2-}$ & H1H3-ACY ${ }^{-}$ & $\mathrm{H} 2 \mathrm{H} 3-\mathrm{ACY}^{-}$ \\
\hline 0.0061 & 0.0097 & 0.0294 & 0.0199 & 0.0424 & 0.0042 \\
\hline
\end{tabular}

very small for the cases of anchoring through the carboxyl group $\left(\mathrm{H} 2-\mathrm{ACY}^{2-}\right.$ and $\left.\mathrm{H} 1 \mathrm{H} 2-\mathrm{ACY}^{-}\right)$and larger in the cases of binding through the hydroxyl group.

As early as 1979, Goodenough and coworkers suggested that the $\pi^{*}$ orbitals of the dicarboxy-bipyridine ligand of the ruthenium(II) dye would promote rapid excited-state electron injection into the conduction band of $\mathrm{TiO}_{2}$ but not that of $\mathrm{SnO}_{2}$ or $\mathrm{ZnO}$ [49]. The reason originated in the difference of symmetry, as the $\mathrm{TiO}_{2}$ conduction band is comprised mainly of unfilled $d$ orbitals where that of $\mathrm{SnO}_{2}$ and $\mathrm{ZnO}$ possesses predominantly $s$-orbital character. The coupling would be optimal when the carboxyl group and the bipyridine are close to coplanarity. In fact, it was shown computationally that the planar geometry enhances the injection [54].

Our results, so far, have shown that the oxygen of the hydroxyl group offers, in the context of a salicylate, a good 
electron transfer pathway, as it preserves the $\pi^{*}$ nature of the dye MO. In contrast, in the case of the adhesion through the sulfonic group, the tetrahedral anchor does not preserve the planar symmetry of the dye. By twisting the lobes of the $p$ orbitals of the oxygen atoms away from the plane of the dye, to insure the proper binding to the neighboring $\mathrm{Ti}(\mathrm{IV})$ ions, the electron transfer pathway is affected, likely causing the lower photovoltaic conversion performance of the actual devices [24]. Although the dyes studied are different from those reported by Chen et al. [27], our results are consistent with theirs in the sense that the DSSC performance depends strongly on the anchoring group types and likely decreases in the order hydroxyl + carboxyl $>$ carboxyl $>$ sulfonate.

\section{Conclusions}

The anchoring modes of the dye onto the $\mathrm{TiO}_{2}$ surface are of crucial importance to the DSSC performance through the bonding type and the extent of electronic coupling between the dye excited state and the conduction band edge of the semiconductor. As most of the theoretical studies so far have focused on sensitizers with carboxyl groups as anchors, we took advantage of the opportunity offered by the protonated form of the Mordant Yellow 10 dye, which has a $-\mathrm{OH},-\mathrm{CO}_{2} \mathrm{H}$ and $-\mathrm{SO}_{3} \mathrm{H}$ groups, to perform a comparative study of the various anchors, binding configurations as well as propensity for electron transfer.

We studied the dye in various single and double deprotonated forms both free and anchored to $\mathrm{a} \mathrm{TiO}_{2}$ nanocluster in various binding configurations. First, we determined the proton affinity to identify the way the dye would tend to deprotonate. Than we studied the distribution of charge on the dye for the key MOs to analyze the intramolecular charge transfer, following a push-pull approach. We also determined the distribution of charge on the anchoring oxygen atoms to get an indication of the likelihood of the transfer to the substrate.

After optimizing the $\mathrm{Ti}_{24} \mathrm{O}_{50} \mathrm{H}_{4}$ nanocluster, we studied the interacting dye-substrate system. The geometry optimization showed, in agreement with other reports, that the carboxyl group tends to bind in bidentate bridging configurations. The salycilate uses both the carboxyl and hydroxyl substituent groups to for either a tridentate binding to adjacent $\mathrm{Ti}(\mathrm{IV})$ ions or a bidentate $\mathrm{Ti}-\mathrm{O}$ binding together with a $\mathrm{O}-$ $\mathrm{H}-\mathrm{O}$ binding, due to the rotation out of the plane of the dye of the carboxyl group. The H-bonds strengthen mechanically the anchoring to the substrate when other binding pathways exist. However, in the absence of $\pi$ binding pathways, the presence of an intermediate $\mathrm{H}$ atom can harm the charge injection. It is the presence of conjugated bonds, allowing for $\pi$ electron delocalization, that facilitates the electron transfer. The sulfonic group prefers a tridentate binding.

To better understand the electron transfer process, we studied the distribution of charge on the cluster, on the entire sensitizer as well as on the various parts of the dye, and on the peripheral oxygen atoms. Inspired by the ideas of Goodenough and coworkers, we discussed the orbital overlap between the $\pi^{*}$ orbital of the dye and the $d$ orbitals of Ti(IV) ion. We showed that the oxygen of the hydroxyl group offers in the context of a salicylate, a good electron transfer pathway, as it preserves the $\pi^{*}$ nature of the dye MO. In contrast, in the case of the anchoring through the sulfonic group, the $p$ orbitals of the oxygen atoms are moved away from the plane of the dye, to insure the proper binding to the neighboring metal ions, affecting the electron transfer pathway. Based on our computational results and analyses, we suggest that the DSSC performance decreases in the order hydroxyl + carboxyl > carboxyl > sulfonate.

\section{Acknowledgments}

The authors acknowledge the financial support from SNSF and UEFISCDI through the joint Grants RSRP IZERO142144/1 and PN-II-Idei-RSRP-1/2012.

\section{References}

[1] M. Grätzel, "Photoelectrochemical cells," Nature, vol. 414, no. 6861, pp. 338-344, 2001.

[2] K. S. Ahn, S. J. Yoo, M. S. Kang, J. W. Lee, and Y. E. Sung, “Tandem dye-sensitized solar cell-powered electrochromic devices for the photovoltaic-powered smart window," Journal of Power Sources, vol. 168, no. 2, pp. 533-536, 2007.

[3] R. Baetens, B. P. Jelle, and A. Gustavsen, "Properties, requirements and possibilities of smart windows for dynamic daylight and solar energy control in buildings: a state-of-the-art review," Solar Energy Materials and Solar Cells, vol. 94, no. 2, pp. 87-105, 2010.

[4] A. Hagfeldt, G. Boschloo, L. Sun, L. Kloo, and H. Pettersson, "Dye-sensitized solar cells," Chemical Reviews, vol. 110, pp. 6595-6663, 2010.

[5] M. K. Nazeeruddin, F. De Angelis, S. Fantacci et al., "Combined experimental and DFT-TDDFT computational study of photoelectrochemical cell ruthenium sensitizers," Journal of the American Chemical Society, vol. 127, no. 48, pp. 16835-16847, 2005.

[6] L. M. Peter, “The Grätzel cell: where next?” Journal of Physical Chemistry Letters, vol. 2, no. 15, pp. 1861-1867, 2011.

[7] B. E. Hardin, H. J. Snaith, and M. D. McGehee, "The renaissance of dye-sensitized solar cells," Nature Photonics, vol. 6, pp. 162169, 2012.

[8] A. Yella, H. W. Lee, H. N. Tsao et al., "Porphyrin-sensitized solar cells with cobalt (II/III)-based redox electrolyte exceed 12 percent efficiency," Science, vol. 334, pp. 629-634, 2011.

[9] S. Ito, S. M. Zakeeruddin, R. Humphry-Baker et al., "Highefficiency organic-dye-sensitized solar cells controlled by nanocrystalline- $\mathrm{TiO}_{2}$ electrode thickness," Advanced Materials, vol. 18, no. 9, pp. 1202-1205, 2006.

[10] S. Hwang, J. H. Lee, C. Park et al., "A highly efficient organic sensitizer for dye-sensitized solar cells," Chemical Communications, no. 46, pp. 4887-4889, 2007.

[11] A. Mishra, M. K. R. Fischer, and P. Büuerle, "Metal-Free organic dyes for dye-Sensitized solar cells: from structure: property relationships to design rules," Angewandte Chemie International Edition, vol. 48, no. 14, pp. 2474-2499, 2009.

[12] T. W. Hamann, R. A. Jensen, A. B. F. Martinson, H. Van Ryswyk, and J. T. Hupp, "Advancing beyond current generation dyesensitized solar cells," Energy and Environmental Science, vol. 1, no. 1, pp. 66-78, 2008. 
[13] J. Lungu, C. I. Oprea, A. Dumbrava et al., "Heterocyclic azodyes as pigments for dye sensitized solar cells-a combined experimental and theoretical study," Journal of Optoelectronics and Advanced Materials, vol. 12, no. 9, pp. 1969-1975, 2010.

[14] K. Kalyanasundaram and M. Grätzel, "Applications of functionalized transition metal complexes in photonic and optoelectronic devices," Coordination Chemistry Reviews, vol. 177, no. 1, pp. 347-414, 1998.

[15] W. M. Campbell, A. K. Burrell, D. L. Officer, and K. W. Jolley, "Porphyrins as light harvesters in the dye-sensitised $\mathrm{TiO}_{2}$ solar cell," Coordination Chemistry Reviews, vol. 248, no. 13-14, pp. 1363-1379, 2004.

[16] E. Galoppini, "Linkers for anchoring sensitizers to semiconductor nanoparticles," Coordination Chemistry Reviews, vol. 248, no. 13-14, pp. 1283-1297, 2004.

[17] S. Ardo and G. J. Meyer, "Photodriven heterogeneous charge transfer with transition-metal compounds anchored to $\mathrm{TiO}_{2}$ semiconductor surfaces," Chemical Society Reviews, vol. 38, no. 1, pp. 115-164, 2009.

[18] P. Falaras, "Synergetic effect of carboxylic acid functional groups and fractal surface characteristics for efficient dye sensitization of titanium oxide," Solar Energy Materials and Solar Cells, vol. 53, no. 1-2, pp. 163-175, 1998.

[19] N. W. Duffy, K. D. Dobson, K. C. Gordon, B. H. Robinson, and A. J. McQuillan, "In situ infrared spectroscopic analysis of the adsorption of ruthenium(II) bipyridyl dicarboxylic acid photosensitisers to $\mathrm{TiO}_{2}$ in aqueous solutions," Chemical Physics Letters, vol. 266, no. 5-6, pp. 451-455, 1997.

[20] T. Ma, K. Inoue, K. Yao et al., "Photoelectrochemical properties of $\mathrm{TiO}_{2}$ electrodes sensitized by porphyrin derivatives with different numbers of carboxyl groups," Journal of Electroanalytical Chemistry, vol. 537, no. 1-2, pp. 31-38, 2002.

[21] Y. X. Weng, L. Li, Y. Liu, L. Wang, and G. Z. Yang, "Surfacebinding forms of carboxylic groups on nanoparticulate $\mathrm{TiO}_{2}$ surface studied by the interface-sensitive transient triplet-state molecular probe," Journal of Physical Chemistry B, vol. 107, no. 18, pp. 4356-4363, 2003.

[22] P. Péchy, F. P. Rotzinger, M. K. Nazeeruddin et al., "Preparation of phosphonated polypyridyl ligands to anchor transition-metal complexes on oxide surfaces: application for the conversion of light to electricity with nanocrystalline $\mathrm{TiO}_{2}$ films," Journal of the Chemical Society, Chemical Communications, no. 1, pp. 6566, 1995.

[23] H. Deng, Y. Zhou, H. Mao, and Z. Lu, "The mixed effect of phthalocyanine and porphyrin on the photoelectric conversion of a nanostructured $\mathrm{TiO}_{2}$ electrode," Synthetic Metals, vol. 92, no. 3, pp. 269-274, 1998.

[24] O. Schwarz, D. Van Loyen, S. Jockusch, N. J. Turro, and H. Dürr, "Preparation and application of new ruthenium(II) polypyridyl complexes as sensitizers for nanocrystalline $\mathrm{TiO}_{2}$," Journal of Photochemistry and Photobiology A, vol. 132, no. 1-2, pp. 91-98, 2000.

[25] J. Moser, S. Punchihewa, P. P. Infelta, and M. Grätzel, "Surface complexation of colloidal semiconductors strongly enhances interfacial electron-transfer rates," Langmuir, vol. 7, no. 12, pp. 3012-3018, 1991.

[26] S. Tunesi and M. A. Anderson, "Surface effects in photochemistry: an in situ cylindrical internal reflection-Fourier transform infrared investigation of the effect of ring substituents on chemisorption onto $\mathrm{TiO}_{2}$ ceramic membranes," Langmuir, vol. 8, no. 2, pp. 487-495, 1992.
[27] Y. S. Chen, C. Li, Z. H. Zeng, W. B. Wang, X. S. Wang, and B. W. Zhang, "Efficient electron injection due to a special adsorbing group's combination of carboxyl and hydroxyl: dye-sensitized solar cells based on new hemicyanine dyes," Journal of Materials Chemistry, vol. 15, no. 16, pp. 1654-1661, 2005.

[28] C. I. Oprea, A. Dumbrava, I. Enache et al., "Role of energy level alignment in solar cells sensitized with a metal-free organic dye: a combined experimental and theoretical approach," Physica Status Solidi A, vol. 208, pp. 2467-2477, 2011.

[29] A. Vittadini, A. Selloni, F. P. Rotzinger, and M. Grätzel, "Formic acid adsorption on dry and hydrated $\mathrm{TiO}_{2}$ anatase (101) surfaces by DFT calculations," Journal of Physical Chemistry B, vol. 104, no. 6, pp. 1300-1306, 2000.

[30] M. Pastore and F. De Angelis, "Computational modelling of $\mathrm{TiO}_{2}$ surfaces sensitized by organic dyes with different anchoring groups: adsorption modes, structure and implication for electron injection/recombination," Physical Chemistry Chemical Physics, vol. 14, pp. 920-928, 2012.

[31] K. Srinivas, K. Yesudas, K. Bhanuprakash, V. J. Rao, and L. Giribabu, "A combined experimental and computational investigation of anthracene based sensitizers for DSSC: comparison of cyanoacrylic and malonic acid electron withdrawing groups binding onto the $\mathrm{TiO}_{2}$ anatase (101) surface," Journal of Physical Chemistry C, vol. 113, no. 46, pp. 20117-20126, 2009.

[32] C. Férez León, L. Kador, B. Peng, and M. Thelakkat, "Characterization of the adsorption of Ru-bpy dyes on mesoporous $\mathrm{TiO}_{2}$ films with UV-Vis, Raman, and FTIR spectroscopies," Journal of Physical Chemistry B, vol. 110, no. 17, pp. 8723-8730, 2006.

[33] N. Martsinovich and A. Troisi, "High-throughput computational screening of chromophores for dye-sensitized solar cells," The Journal of Physical Chemistry C, vol. 115, pp. 11781-11792, 2011.

[34] S. J. Moon, J. H. Yum, R. Humphry-Baker et al., "Highly efficient organic sensitizers for solid-state dye-sensitized solar cells," Journal of Physical Chemistry C, vol. 113, no. 38, pp. 16816-16820, 2009.

[35] F. De Angelis, S. Fantacci, and A. Selloni, “Alignment of the dye's molecular levels with the $\mathrm{TiO}_{2}$ band edges in dye-sensitized solar cells: a DFT-TDDFT study," Nanotechnology, vol. 19, no. 42, Article ID 424002, 2008.

[36] P. Hohenberg and W. Kohn, "Inhomogeneous electron gas," Physical Review, vol. 136, pp. B864-B871, 1964.

[37] W. Kohn and L. J. Sham, "Self-consistent equations including exchange and correlation effects," Physical Review, vol. 140, pp. A1133-A1138, 1965.

[38] R. G. Parr and W. Yang, Density-Functional Theory of Atoms and Molecules, Oxford University Press, New York, NY, USA, 1989.

[39] A. D. Becke, "Density-functional thermochemistry. III. The role of exact exchange," The Journal of Chemical Physics, vol. 98, no. 7, pp. 5648-5652, 1993.

[40] C. Lee, W. Yang, and R. G. Parr, "Development of the ColleSalvetti correlation-energy formula into a functional of the electron density," Physical Review B, vol. 37, no. 2, pp. 785-789, 1988.

[41] V. A. Rassolov, M. A. Ratner, J. A. Pople, P. C. Redfern, and L. A. Curtiss, "6-31G* basis set for third-row atoms," Journal of Computational Chemistry, vol. 22, no. 9, pp. 976-984, 2001.

[42] V. Barone and M. Cossi, "Quantum calculation of molecular energies and energy gradients in solution by a conductor solvent model," The Journal of Physical Chemistry A, vol. 102, pp. 19952001, 1998. 
[43] J. Tomasi, B. Mennucci, and R. Cammi, "Quantum mechanical continuum solvation models," Chemical Reviews, vol. 105, pp. 2999-3093, 2005.

[44] M. E. Casida, C. Jamorski, K. C. Casida, and D. R. Salahub, "Molecular excitation energies to high-lying bound states from time-dependent density-functional response theory: characterization and correction of the time-dependent local density approximation ionization threshold," Journal of Chemical Physics, vol. 108, no. 11, pp. 4439-4449, 1998.

[45] N. Godbout, D. R. Salahub, J. Andzelm, and E. Wimmer, "Optimization of Gaussian-type basis sets for local spin density functional calculations. Part I. Boron through neon, optimization technique and validation," Canadian Journal of Chemistry, vol. 70, no. 2, pp. 560-571, 1992.

[46] M. J. Frisch, G. W. Trucks, H. B. Schlegel et al., Gaussian 03, Revision C.02, Gaussian Inc., Wallingford, Conn, USA, 2004.

[47] F. De Angelis, "Direct vs. indirect injection mechanisms in perylene dye-sensitized solar cells: a DFT/TDDFT investigation," Chemical Physics Letters, vol. 493, no. 4-6, pp. 323-327, 2010.

[48] D. Matthews, P. Infelta, and M. Grätzel, "Calculation of the photocurrent-potential characteristic for regenerative, sensitized semiconductor electrodes," Solar Energy Materials and Solar Cells, vol. 44, no. 2, pp. 119-155, 1996.

[49] S. Anderson, E. C. Constable, M. P. Dare-Edwards et al., "Chemical modification of a titanium (IV) oxide electrode to give stable dye sensitisation without a supersensitiser," Nature, vol. 280, no. 5723, pp. 571-573, 1979.

[50] A. Selloni, "Crystal growth: anatase shows its reactive side," Nature Materials, vol. 7, no. 8, pp. 613-615, 2008.

[51] C. I. Oprea, P. Panait, F. Cimpoesu, M. Ferbinteanu, and M. A. Girtu, "Density functional theory (DFT) study of coumarinbased dyes adsorbed on $\mathrm{TiO}_{2}$ nanoclusters-applications to dye-sensitized solar cells," Materials, 2013.

[52] F. De Angelis, S. Fantacci, A. Selloni, M. K. Nazeeruddin, and M. Grätzel, "First-principles modeling of the adsorption geometry and electronic structure of $\mathrm{Ru}(\mathrm{II})$ dyes on extended $\mathrm{TiO}_{2}$ substrates for dye-sensitized solar cell applications," Journal of Physical Chemistry C, vol. 114, no. 13, pp. 6054-6061, 2010.

[53] M. J. Lundqvist, M. Nilsing, P. Persson, and S. Lunell, "DFT study of bare and dye-sensitized $\mathrm{TiO}_{2}$ clusters and nanocrystals," International Journal of Quantum Chemistry, vol. 106, no. 15, pp. 3214-3234, 2006.

[54] P. Persson, S. Lunell, and L. Ojamäe, "Electronic interactions between aromatic adsorbates and metal oxide substrates calculated from first principles," Chemical Physics Letters, vol. 364, no. 5-6, pp. 469-474, 2002. 

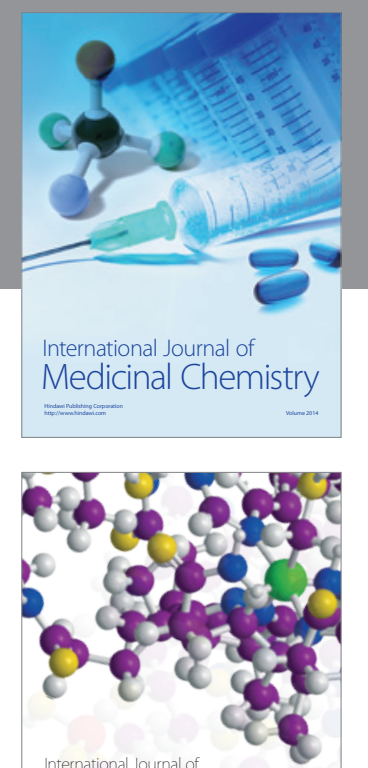

\section{Carbohydrate} Chemistry

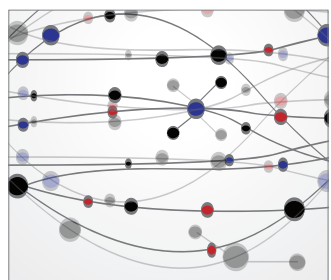

The Scientific World Journal
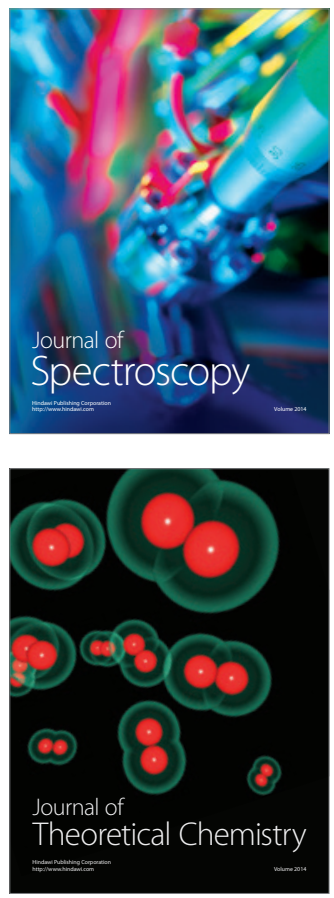
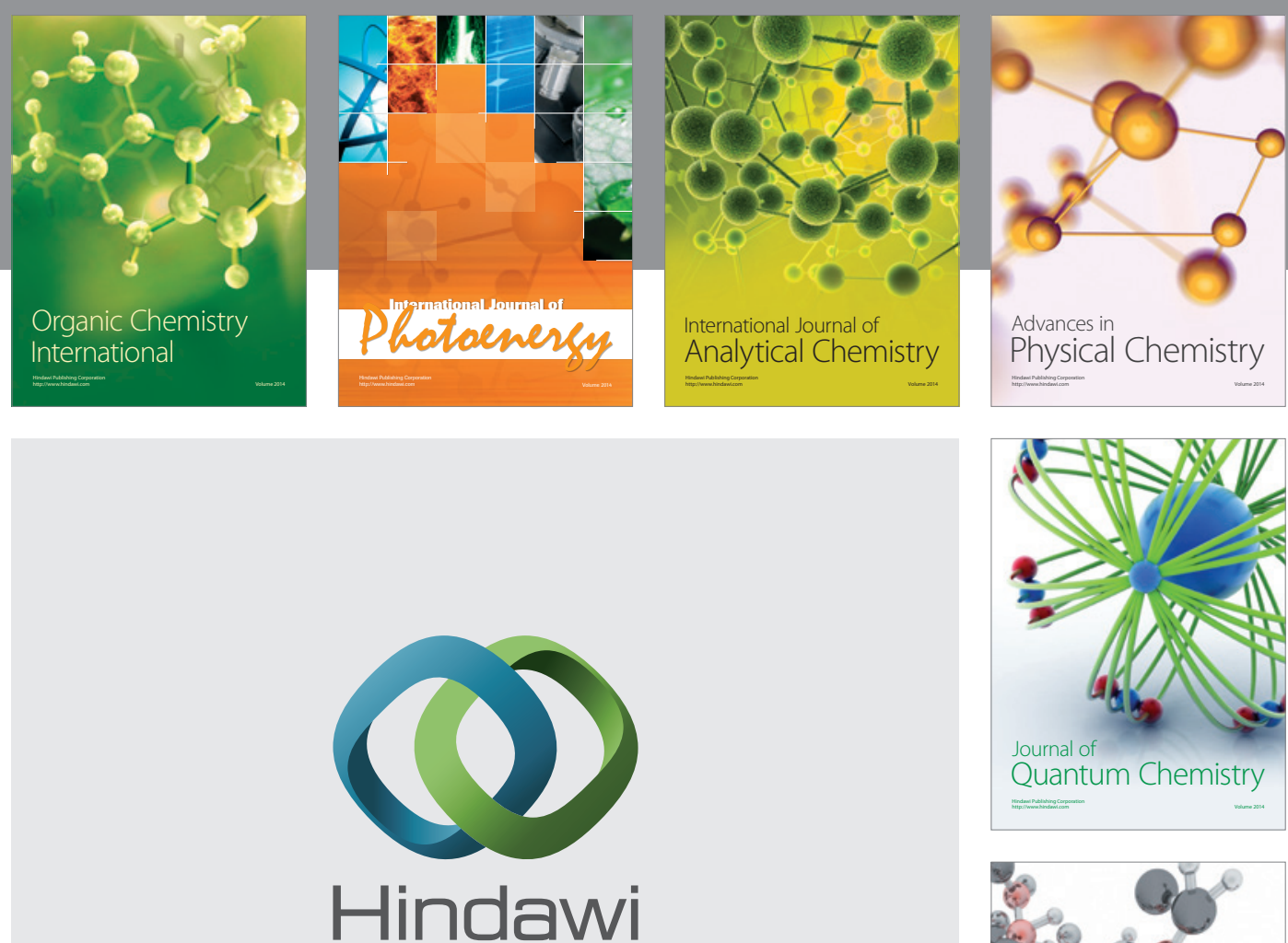

Submit your manuscripts at

http://www.hindawi.com

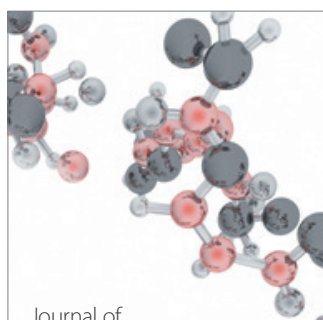

Analytical Methods

in Chemistry

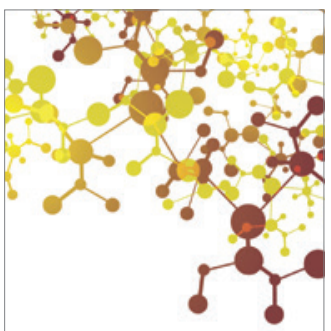

Journal of

Applied Chemistry

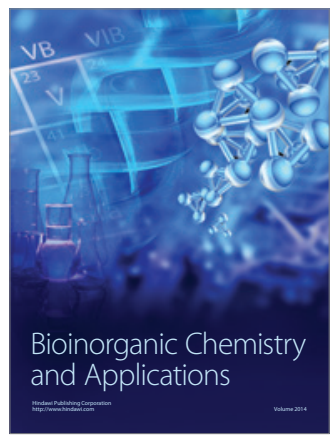

Inorganic Chemistry
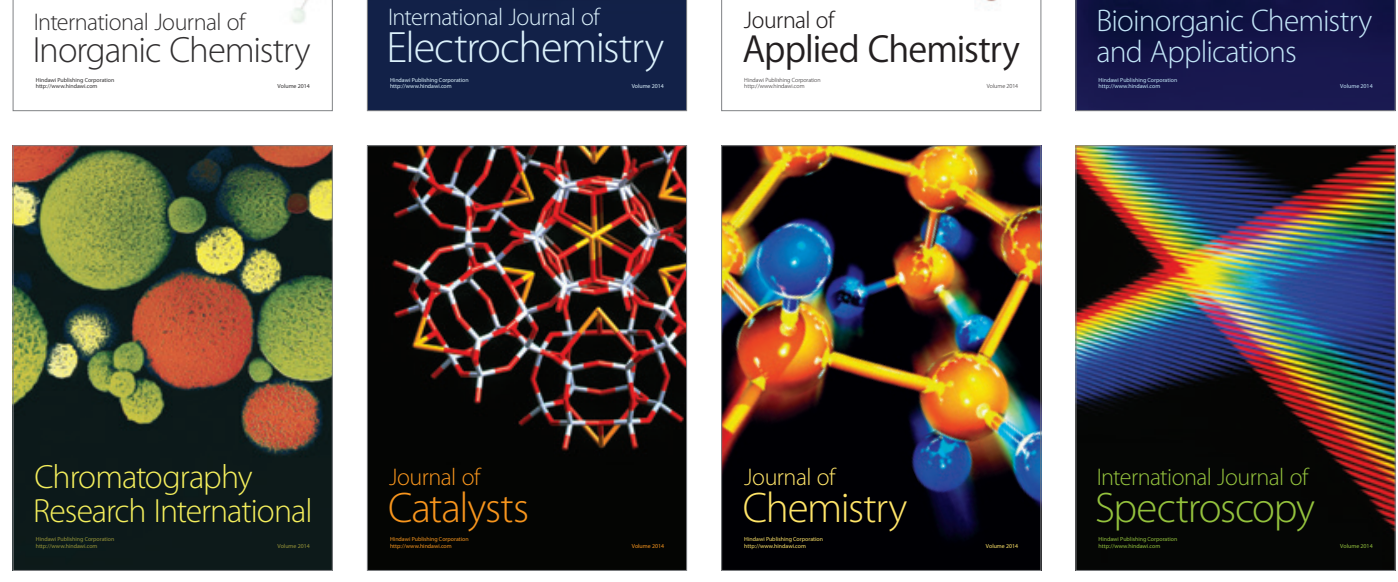